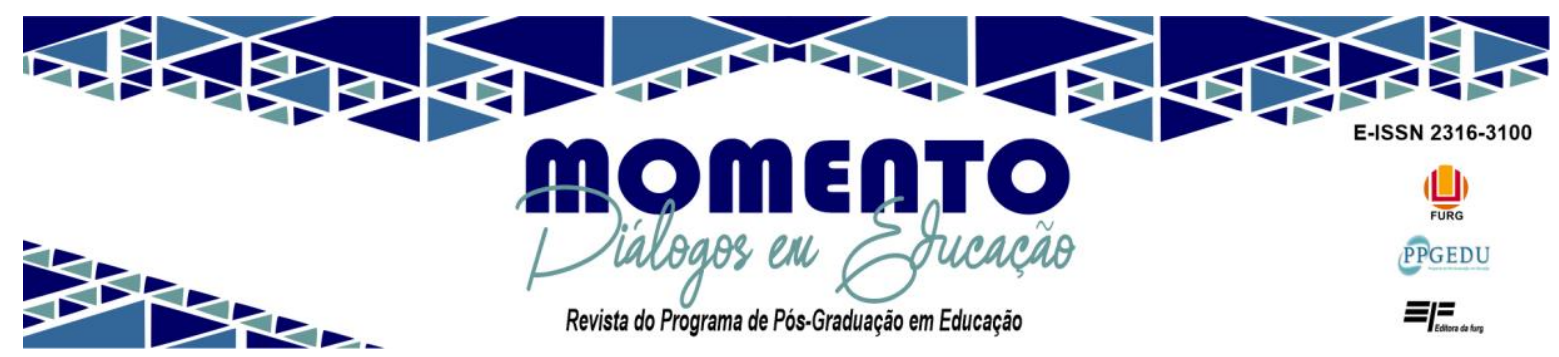

\title{
PRODUÇÃO CIENTÍFICA SOBRE EDUCAÇÃO FÍSICA NA EDUCAÇÃO INFANTIL A PARTIR DOS PERIÓDICOS BRASILEIROS DA ÁREA
}

\author{
Gabriela Souza Pinheiro ${ }^{1}$ \\ Vânia de Fátima Matias de Souza ${ }^{2}$ \\ Patric Paludett Flores ${ }^{3}$
}

Resumo: O presente estudo objetivou levantar a produção científica dos periódicos nacionais da área de Educação Física, no período de 2008-2018, sobre a Educação Física na Educação Infantil. Destaca-se que esta pesquisa é do tipo revisão integrativa, na qual foram analisados artigos científicos publicados em 14 revistas nacionais, classificadas com Qualis B2 ou superior, que contemplam em seu escopo a área da Educação Física. Foram encontrados 668 artigos que passaram por critérios de inclusão e exclusão, sendo selecionados no final 34 artigos. Após a seleção dos artigos, a análise constituiu-se a partir dos indicativos da análise por temáticas, possibilitando a criação de três sessões de análise: a) mapeamento dos autores das produções sobre Educação Física na Educação Infantil; b) procedimentos metodológicos abordados nas produções sobre Educação Física na Educação Infantil; e c) principais temáticas abordadas nas pesquisas selecionadas a respeito da Educação Física na Educação Infantil. A partir dos resultados, identificou-se que o Sudeste é a região com mais pesquisadores que abordam a temática; a maioria das pesquisas adotou os pressupostos da pesquisa qualitativa para desenvolver seus estudos; e, em relação às temáticas, foram evidenciadas cinco categorias principais, sendo elas: Possibilidades Pedagógicas, Formação Profissional, Inclusão Escolar, Documentos Norteadores e Manifestações Corporais. De modo geral, as temáticas refletiram a importância de se ter um profissional de Educação Física inserido na Educação Infantil, a fim de potencializar o desenvolvimento das crianças nessa etapa do ensino, a partir de um contexto teórico e prático da disciplina para o desenvolvimento e condução dos conhecimentos que emergem da área.

Palavras-chave: Produção Científica. Educação Física. Educação Infantil. Periódicos Brasileiros.

\section{SCIENTIFIC PRODUCTION ON PHYSICAL EDUCATION IN EARLY CHILDHOOD EDUCATION FROM BRAZILIAN JOURNALS IN THE FIELD}

\begin{abstract}
This study aimed to survey the scientific production of national journals in the field of Physical Education, in the period 2008-2018, on Physical Education in Early Childhood Education. It is noteworthy that this research is the integrative review type, in which the scientific articles analyzed are published in 14 national journals that have in their scope the field of Physical Education. A total of 668 articles were found, which underwent inclusion and exclusion criteria, and 34 articles were selected at the end. The analysis of the articles is constituted from the indications of the analysis by themes, enabling the creation of three session: a) mapping of the authors of the selected production; b) methodological procedures addressed in the selected production; and, c) main themes addressed in the selected research. From the results, it was identified that the southeast region is the

\footnotetext{
${ }^{1}$ Licenciada em Educação Física pela Universidade Estadual do Paraná (UNESPAR).

${ }^{2}$ Licenciada em Educação Física pela Universidade Estadual de Londrina (UEL). Mestra em Educação Física pela Universidade Estadual de Maringá (UEM). Doutora em Educação pela Universidade Estadual de Maringá (UEM). Professora do Departamento de Educação Física da Universidade Estadual de Maringá (DEF/UEM). ${ }^{3}$ Licenciado em Educação Física pela Universidade Federal de Santa Maria (UFSM). Mestre em Educação pela Universidade Federal de Santa Maria (UFSM). Doutor em Educação Física pela Universidade Estadual de Maringá (UEM). Professor do Departamento de Ciências do Movimento Humano da Universidade do Estado de Minas Gerais (DCMH/UEMG).
} 


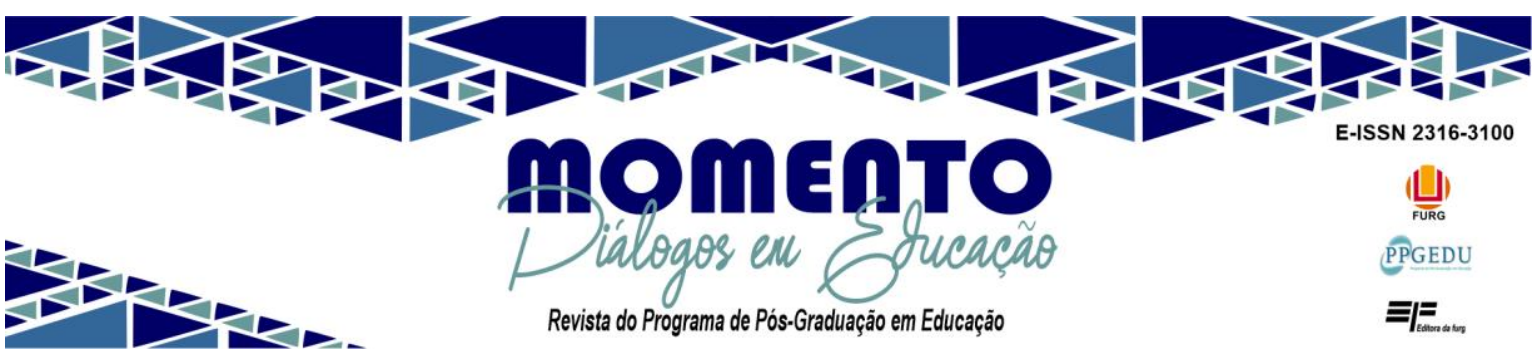

region with more researchers on the subject; that most studies adopted the assumptions of qualitative research to develop their studies; and, regarding the themes, five main categories emerged, being: Pedagogical Possibilities, Professional Education, School Inclusion, Guidelines Documents and Body Manifestations. The themes addressed generally reflected the importance of having a Physical Education professional inserted in this learning stage to enhance the development of children in Early Childhood Education starting from a theoretical and practical context of the discipline to the development and conduction of knowledge that emerges from the field.

Keywords: Scientific Production. Physical Education. Early Childhood Education. Brazilian Periodicals.

\section{PRODUCCIÓN CIENTÍFICA SOBRE EDUCACIÓN FÍSICA EN EDUCACIÓN INFANTIL DE LAS REVISTAS BRASILEÑAS DEL CAMPO}

Resumen: Este estudio buscó relevar la producción científica de revistas brasileñas del campo de la Educación Física, en el período 2008-2018, sobre Educación Física en Educación Infantil. Es de destacar que esta investigación es del tipo revisión integradora, en el que se analizaron artículos científicos de 14 revistas vinculadas al campo de la Educación Física. Se encontraron un total de 668 artículos, los cuales fueron sujetos según criterios de inclusión y exclusión, con 34 artículos seleccionados al final. El análisis de los artículos se basó en el indicativo del análisis por temáticas, lo que permitió la creación de tres sesiones: a) mapeo de los autores de la producción seleccionada; b) procedimientos metodológicos abordados en la producción seleccionada; y, c) los principales temas abordados en la investigación seleccionada. A partir de los resultados, se identificó que la región sureste de Brasil es la región con más investigadores en el tema; que la mayoría de las investigaciones han adoptado los supuestos de la investigación cualitativa para desarrollar sus estudios; y, en relación a los temas, surgieron cinco categorías principales, a saber: Posibilidades Pedagógicas, Formación Profesional, Inclusión Escolar, Documentos Rectores y Manifestaciones Corporales. Los temas abordados, reflejaron en general la importancia de contar con un profesional de la Educación Física insertado en esta etapa docente para potenciar el desarrollo de los niños, a partir de un contexto teórico y práctico de la disciplina para el desarrollo y conducción de los conocimientos que surgen del área.

Palabras clave: Producción Científica; Educación Física; Educación Infantil; Revista Científica Brasileña.

\section{Introdução}

Sabe-se que a Educação Física é uma área do conhecimento humano ligada às práticas corporais historicamente produzidas pela humanidade, isto é, ela faz parte da cultura do homem (BRASIL, 2017). Por meio do movimento humano, das atividades culturais e suas finalidades, a área busca tematizar as manifestações que constituem as unidades temáticas dos jogos e brincadeiras, lutas, ginásticas, danças, esportes e práticas corporais de aventura.

Partindo do pressuposto de que a Educação Física tem como objeto de conhecimento 


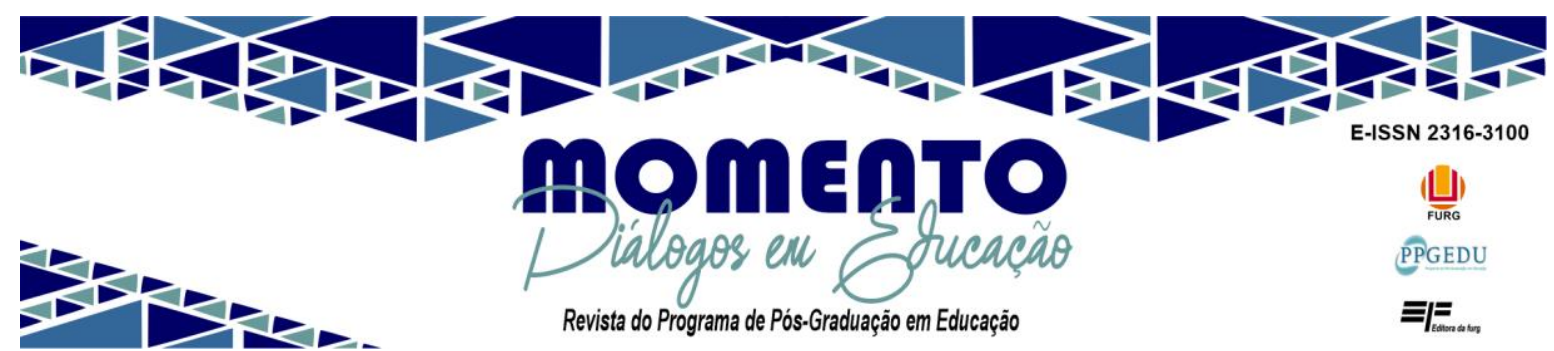

a cultura corporal de movimento, destaca-se a necessidade de uma sistematização desse conhecimento e entende-se que o processo de ensino e aprendizagem, ao longo da escolarização, precisa proporcionar aos indivíduos saberes suficientes com relação a essa cultura. Com isso, torna-se essencial o desenvolvimento da autonomia dos alunos para o mundo do movimento humano, a fim de construir caminhos a serem trilhados dentro e fora da escola (BRASIL, 2017).

Nesta direção, pode-se compreender a relevância da Educação Física em todas as etapas de ensino da Educação Básica e seus reflexos para a vida dos sujeitos que são perpassados por esse componente (PALMA, OLIVEIRA, PALMA, 2010). Assim, nota-se que essa área do conhecimento precisa ter uma organização e sistematização que exponha os saberes e competências que precisam ser trabalhados na Educação Infantil, no Ensino Fundamental - Anos Iniciais e Anos Finais - no Ensino Médio e nas diferentes modalidades de ensino (Educação de Jovens e Adultos, Educação Especial, etc.), de forma que seja possível nortear as ações interventivas na prática pedagógica de cada professor de Educação Física. Ressalta-se que, para este trabalho, optou-se por focalizar a Educação Física em apenas uma dessas etapas de ensino: a Educação Infantil.

A Educação Física na Educação Infantil (etapa que compreende a idade de 0 a 5 anos e 11 meses), desde a implantação da Lei de Diretrizes e Bases da Educação Nacional (LDBEN) n. 9.394/96 (BRASIL, 1996), vem sendo motivo de discussões políticas, educacionais e acadêmicas sobre a necessidade de tematizar o movimento humano a partir dos indicativos da área da Educação Física, bem como a necessidade de ter ou não um professor específico dessa área de conhecimento (AYOUB, 2001; FARIAS et al, 2019). Em termos legais, sobre a atuação do professor de Educação Física na Educação Infantil, a LDBEN não garante essa obrigatoriedade, no entanto, impulsiona a presença dessa área do conhecimento na primeira etapa da Educação Básica. Segundo Martins (2018, p. 32), nesse terreno legal-normativo, outro documento que também se configura como uma possível influência para a inserção da Educação Física na Educação Infantil, em especial do professor específico da área, é a "Lei do Piso" que, "ao estabelecer patamares de remuneração mínima para os professores de todo o País [...] também assegura aos docentes da Educação Básica um terço de sua carga horária semanal destinada às atividades extraclasse, quais sejam de estudos, planejamento e avaliação". Essa regulamentação fez com que boa parte dos 


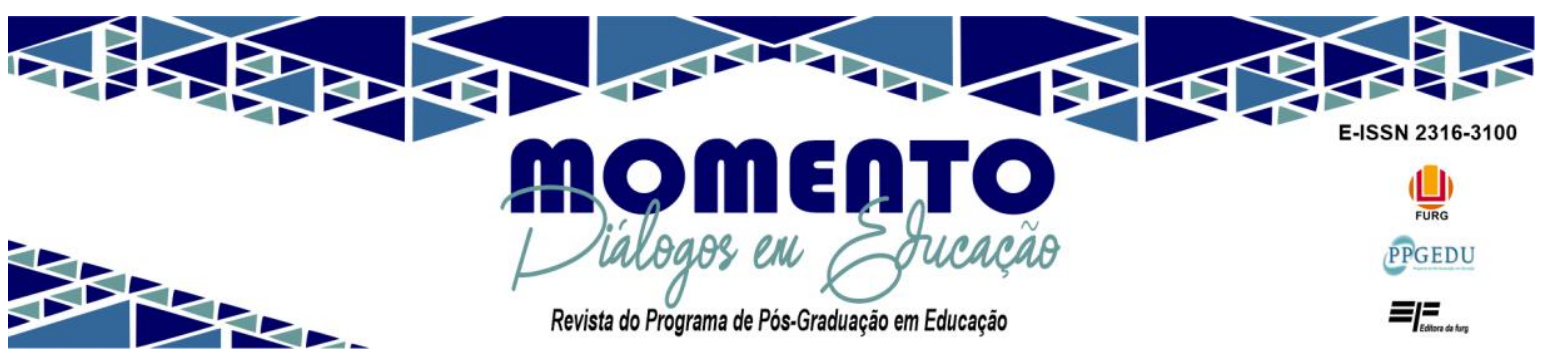

municípios optassem pela Educação Física como atividade extraclasse, impulsionando a sua inserção nesta etapa.

No entanto, ressalta-se que a Educação Física deve estar integrada à proposta pedagógica da escola, vinculada como um componente curricular obrigatório da Educação Infantil, garantindo o acesso à cultura corporal de movimento, de acordo com as faixas etárias e condições da população escolar atendida. Conforme Gallahue, Ozmun e Goodway (2013) a Educação Infantil tem um papel primordial no desenvolvimento motor, cognitivo e afetivo social da criança que frequenta essa etapa do ensino, pois nessa fase se concretiza a aquisição das habilidades motoras fundamentais, a socialização e interação interpessoal e a compreensão/internalização dos conhecimentos escolares.

De acordo com Mello et al (2020), estudos e pesquisas práticas assentadas em experiências pedagógicas, tais como a pesquisa realizada pelos autores que retrata a realidade de um Centro Municipal de Educação Infantil (CMEI) de Vitória/ES, demonstraram a importância de haver, na Educação Infantil, um profissional com formação específica acerca da cultura corporal de movimento; Mello et al (2020) discorre sobre o trabalho conjunto da Educação Física não como disciplina, mas sim como área de conhecimento na Educação Infantil, através de atividades lúdicas dentro e fora da sala de aula, edificando as estratégias metodológicas para determinados fins no desenvolvimento das crianças. Diante disso, é preciso direcionar olhares para esse momento do ensino e compreender que há muitas potencialidades para serem desenvolvidas e trabalhadas com os sujeitos que nele estão inseridos.

Martins (2018) destaca que as bases legais apresentadas no processo de sistematização e organização do ensino na Educação Básica, como o Referencial Curricular Nacional para a Educação Infantil (RCNEI) (BRASIL, 1998), as Diretrizes Curriculares Nacionais para a Educação Infantil (DCNEI) (BRASIL, 2013) e a Base Nacional Comum Curricular (BNCC) (BRASIL, 2017) trazem indicativos da implantação da Educação Física na Educação Infantil de maneira efetiva, porém ainda não há garantia da inserção dessa área, com professores específicos, nessa etapa da escolarização. Um dos condicionantes para tal situação, conforme Silveira e Bom (2017), configura-se pela falta de segurança dos professores na inserção e legitimação da Educação Física na Educação Infantil, bem como 


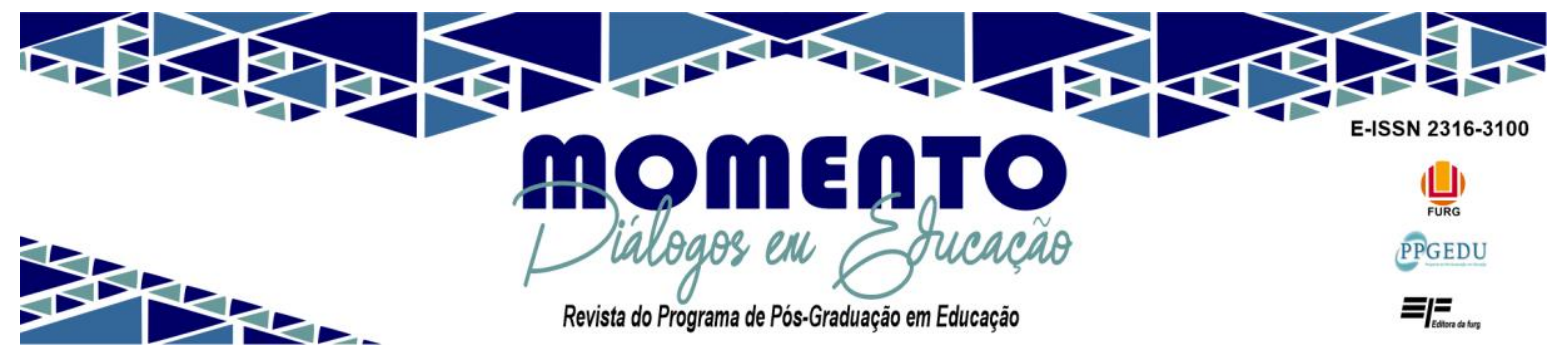

pela falta de conhecimento dos mesmos sobre essa primeira etapa da Educação Básica.

Nesse sentido, na formação em Educação Física, ainda existem lacunas a serem preenchidas no que diz respeito ao conhecimento produzido pelas pesquisas acadêmicas voltadas à escola; ressalta-se que pouco se tem feito no campo científico e acadêmico, na tentativa de minimizar tais problemáticas que emergem da narrativa apresentada na Educação Infantil e sua relação com a Educação Física, principalmente, sobre o que se tem de publicação acerca do conhecimento da área (MARTINS, BARBOSA, MELLO, 2018). Assim, destaca-se que é necessário refletir a respeito da produção do conhecimento sobre a Educação Física escolar na Educação Infantil, o que nos leva a pensar como problemática de estudo: o que vem sendo produzido enquanto conhecimento científico na área da Educação Física escolar brasileira no que se refere à Educação Infantil?

Para responder a essa questão, o presente trabalho tem como objetivo levantar a produção científica dos periódicos nacionais da área da Educação Física que aborda a Educação Física escolar na Educação Infantil, considerando como recorte temporal o período de 2008-2018.

\section{Metodologia}

Este estudo se caracteriza como uma revisão integrativa de literatura. A revisão integrativa de literatura "[...] é a mais ampla abordagem metodológica referente às revisões, permitindo a inclusão de estudos experimentais e não-experimentais para uma compreensão completa do fenômeno analisado" (SOUZA, SILVA, CARVALHO, 2010, p. 103). Entretanto, para as autoras, o pesquisador pode construir uma revisão integrativa de literatura teórica e empírica com diferentes finalidades, as quais podem traçar a definição de conceitos, revisão de teorias e análises de problemas metodológicos.

Para definir as bases de dados exploradas no estudo, inicialmente, foi realizado um levantamento dos principais periódicos nacionais da área de Educação Física. Como a pesquisa buscou fazer um mapeamento da produção no período de 2008 a 2018, optou-se por selecionar as revistas classificadas com Qualis B2 ou superior, de acordo com a avaliação da Plataforma Sucupira da CAPES, no quadriênio 2012-2016.

Assim, a partir dos critérios estabelecidos, foram selecionadas 14 revistas, a saber: 


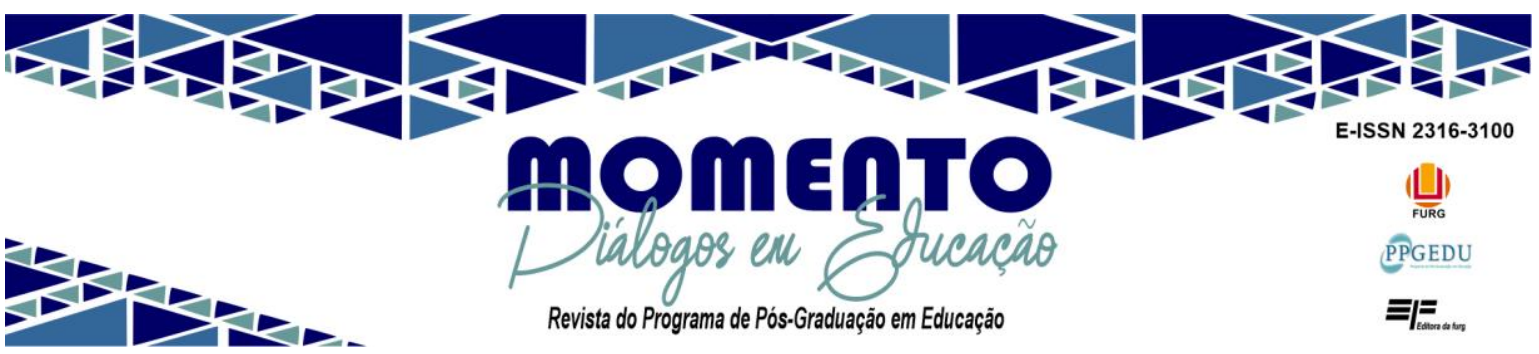

Movimento, Revista Brasileira de Medicina do Esporte (RBME), Motriz, Revista Brasileira de Ciências do Esporte (RBCE), Revista Brasileira de Educação Física e Esporte (RBEFE), Journal of Physical Education/Revista da Educação Física - UEM (REF-UEM), Motricidade, Revista Brasileira de Cineantropometria e Desempenho Humano (RBCDH), Motrivivência, Pensar a Prática, Licere, Revista Brasileira de Atividade Física e Saúde (RBAFS), Revista Brasileira de Biomecânica (RBB) e Revista Brasileira de Ciência e Movimento (RBCM).

Na sequência da seleção das revistas, realizou-se o levantamento dos artigos. Nesse sentido, para realizar a busca da produção foco deste estudo, foi necessário entrar na plataforma de cada periódico e realizar a busca da produção científica. Destaca-se que, para efetuar a busca, utilizou-se como descritor o termo Educação Infantil.

Para a seleção dos artigos, estes foram submetidos aos critérios de inclusão e exclusão. Para o artigo ser incluído, ele deveria: a) retratar a Educação Física na Educação Infantil; b) ser um artigo original; c) ter sido publicado no período de 2008-2018; e d) ser um artigo disponível na íntegra. Os artigos que não atenderam aos critérios acima descritos foram excluídos por serem: a) artigos que não abordam a Educação Física na Educação Infantil; b) artigos fora do período selecionado para análise; c) artigos de revisão/ensaios/resenhas; e d) artigos indisponíveis na íntegra. Nesse sentido, foram encontrados 668 artigos que foram analisados seguindo os critérios de inclusão e exclusão (Figura 1). 


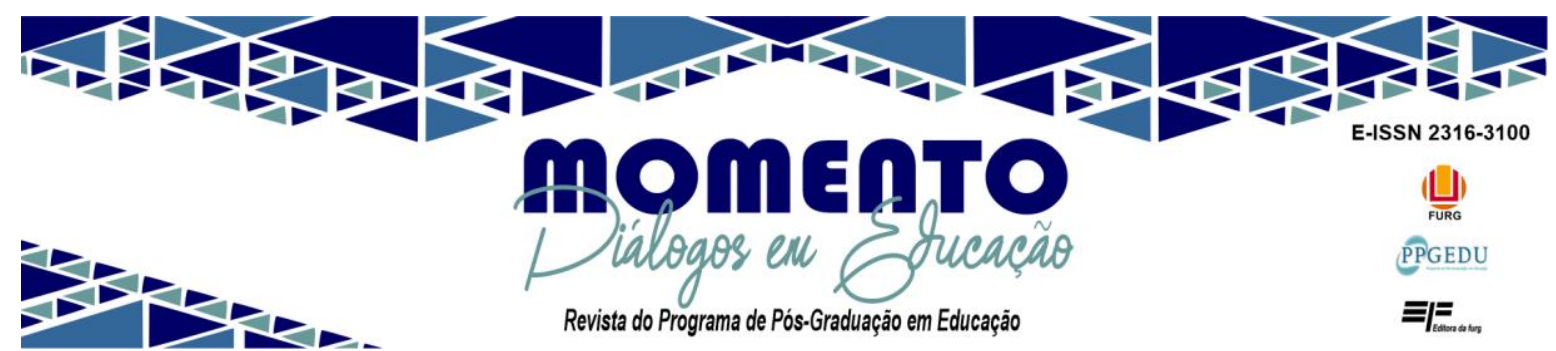

Figura 1: Fluxograma da seleção dos artigos.

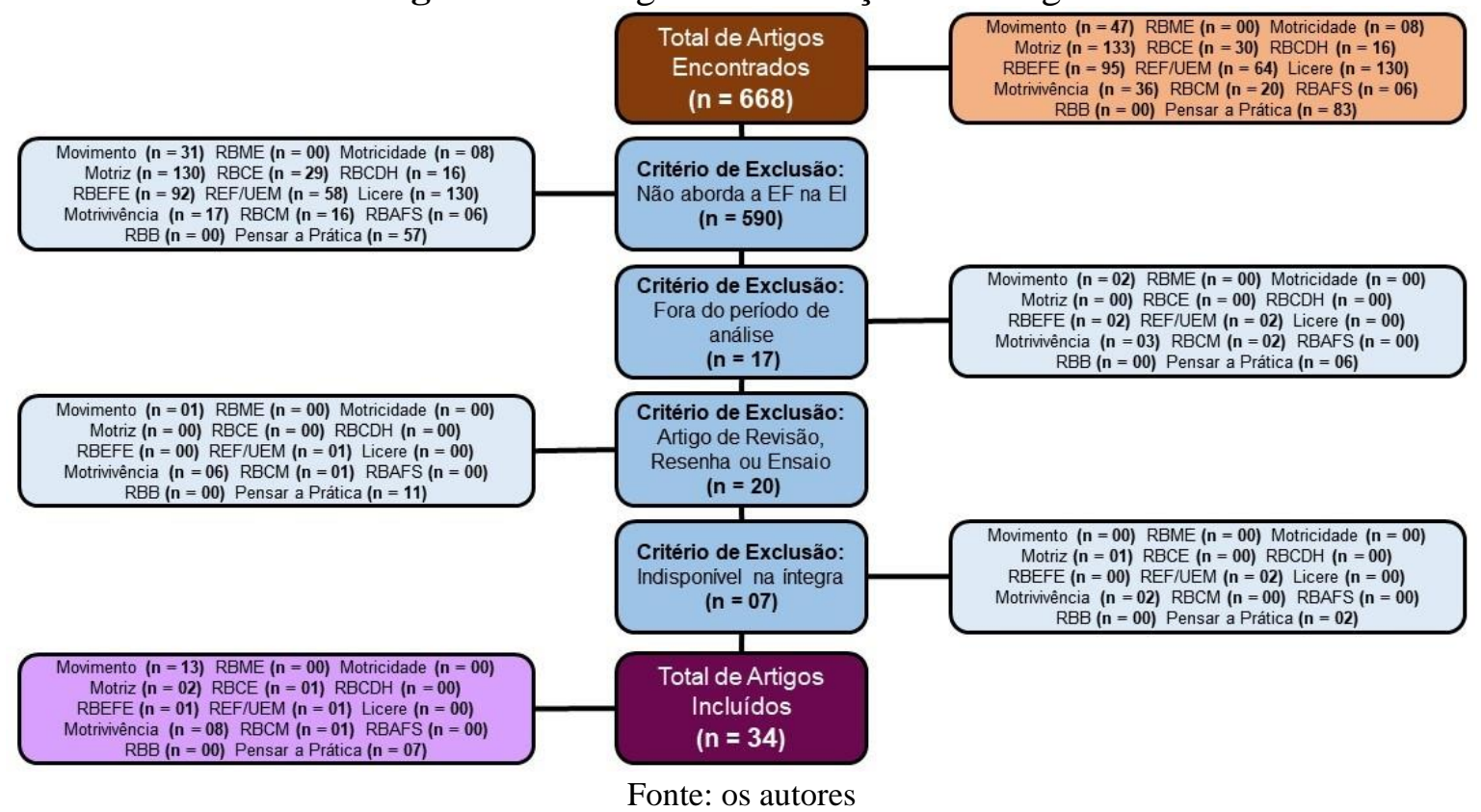

Após o levantamento e processo de análise das produções, foram selecionados 34 artigos (Quadro 1), os quais foram submetidos aos princípios da análise de conteúdo, em especial, baseados no método de Richardson (2017). O autor propõe a análise por meio das temáticas fundamentadas através de categorizações. Isso quer dizer que foram criadas categorias para determinadas temáticas em comum e, por meio delas podem ser definidas classificações de assuntos, o que permite ao pesquisador isolar temas de registro e retirar partes que irão auxiliar na interpretação dos resultados do estudo. 


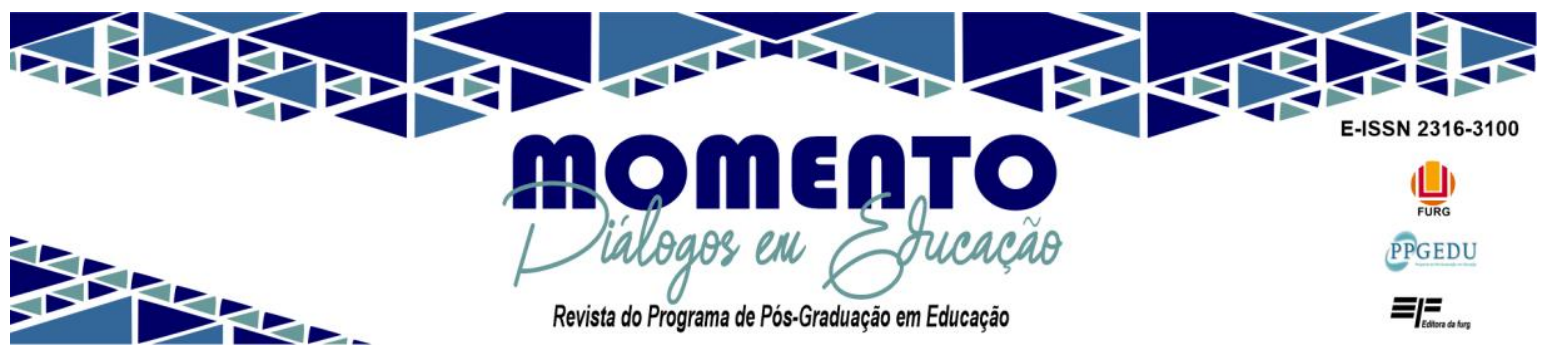

Quadro 1: Lista da produção científica selecionada.

\begin{tabular}{|c|c|c|c|}
\hline Revista & $\begin{array}{c}\mathrm{N}^{\mathbf{o}} \\
\text { Artigo }\end{array}$ & Autoria/Ano & Título do Artigo/DOI \\
\hline \multirow{13}{*}{ Movimento } & 1 & $\begin{array}{l}\text { Hirai e Cardoso } \\
\qquad(2009)\end{array}$ & $\begin{array}{l}\text { Possibilidades para o Ensino Orientado na } \\
\text { Problematização: Para a Realização da Concepção de } \\
\text { Aulas Abertas às Experiências } \\
\text { (https://doi.org/10.22456/1982-8918.2432) }\end{array}$ \\
\hline & 2 & $\begin{array}{l}\text { Spessato et al. } \\
\qquad(2009)\end{array}$ & $\begin{array}{c}\text { Educação infantil e intervenção motora: um olhar a } \\
\text { partir da teoria bioecológica de Bronfenbrenner } \\
\text { (https://doi.org/10.22456/1982-8918.5617) }\end{array}$ \\
\hline & 3 & $\begin{array}{l}\text { Richter e Vaz } \\
\qquad(2010)\end{array}$ & $\begin{array}{c}\text { Educação Física, educação do corpo e pequena infância: } \\
\text { interfaces e contradições na rotina de uma creche } \\
\text { (https://doi.org/10.22456/1982-8918.7565) }\end{array}$ \\
\hline & 4 & $\begin{array}{c}\text { Chicon e Sá } \\
\text { (2011) }\end{array}$ & $\begin{array}{c}\text { Inclusão na educação física escolar: considerações } \\
\text { sobre a constituição da subjetividade humana } \\
\text { (https://doi.org/10.22456/1982-8918.12382) }\end{array}$ \\
\hline & 5 & $\begin{array}{l}\text { Rodrigues e } \\
\text { Figueiredo } \\
\quad(2011)\end{array}$ & $\begin{array}{l}\text { Construção identitária da professora de Educação } \\
\text { Física em uma instituição de educação infantil } \\
\text { (https://doi.org/10.22456/1982-8918.20377) }\end{array}$ \\
\hline & 6 & $\begin{array}{l}\text { Andrade Filho } \\
\qquad(2013)\end{array}$ & $\begin{array}{l}\text { Observação compreensivo-crítica das experiências de } \\
\text { movimento corporal das crianças na educação infantil } \\
\text { (https://doi.org/10.22456/1982-8918.26491) }\end{array}$ \\
\hline & 7 & $\begin{array}{l}\text { Chicon, Sá e } \\
\text { Fontes (2013) }\end{array}$ & $\begin{array}{l}\text { Atividades lúdicas no meio aquático: possibilidades } \\
\text { para a inclusão } \\
\text { (https://doi.org/10.22456/1982-8918.29595) }\end{array}$ \\
\hline & 8 & $\begin{array}{l}\text { Chicon et al } \\
\text { (2016) }\end{array}$ & $\begin{array}{l}\text { Educação Física e inclusão: a mediação pedagógica do } \\
\text { professor na brinquedoteca } \\
\text { (https://doi.org/10.22456/1982-8918.56302) }\end{array}$ \\
\hline & 9 & $\begin{array}{l}\text { Soares, } \\
\text { Prodócimo e } \\
\text { Marco }(2016)\end{array}$ & $\begin{array}{l}\text { O diálogo na Educação Infantil: o movimento, a } \\
\text { interdisciplinaridade e a Educação Física } \\
\text { (https://doi.org/10.22456/1982-8918.57571) }\end{array}$ \\
\hline & 10 & $\begin{array}{l}\text { Surdi, Melo e } \\
\text { Kunz (2016) }\end{array}$ & $\begin{array}{l}\text { O brincar e o se-movimentar nas aulas de Educação } \\
\text { Física Infantil: realidades e possibilidades } \\
\text { (https://doi.org/10.22456/1982-8918.58076) }\end{array}$ \\
\hline & 11 & $\begin{array}{l}\text { Gonçalves, } \\
\text { Gomes-da-Silva e } \\
\text { Andrade (2017) }\end{array}$ & $\begin{array}{l}\text { No princípio é o ludens: integração do self do bebê } \\
\text { através do brincar em creche } \\
\text { (https://doi.org/10.22456/1982-8918.64286) }\end{array}$ \\
\hline & 12 & $\begin{array}{l}\text { Barbosa, Martins } \\
\text { e Mello (2017) }\end{array}$ & $\begin{array}{l}\text { Brincadeiras lúdico-agressivas: tensões e } \\
\text { possibilidades no cotidiano na Educação Infantil } \\
\text { (https://doi.org/10.22456/1982-8918.65259) }\end{array}$ \\
\hline & 13 & $\begin{array}{c}\text { Tonietto e } \\
\text { Garanhani (2017) }\end{array}$ & $\begin{array}{l}\text { A cultura infantil e a relação com os saberes da } \\
\text { Educação Física na Escola } \\
\text { (https://doi.org/10.22456/1982-8918.66236) }\end{array}$ \\
\hline RBEFE & 14 & $\begin{array}{l}\text { Macedo e Neira } \\
\qquad(2017)\end{array}$ & $\begin{array}{l}\text { A Educação Física na creche: tematizando as práticas } \\
\text { corporais } \\
\text { (https://doi.org/10.11606/18075509201700010099) }\end{array}$ \\
\hline
\end{tabular}




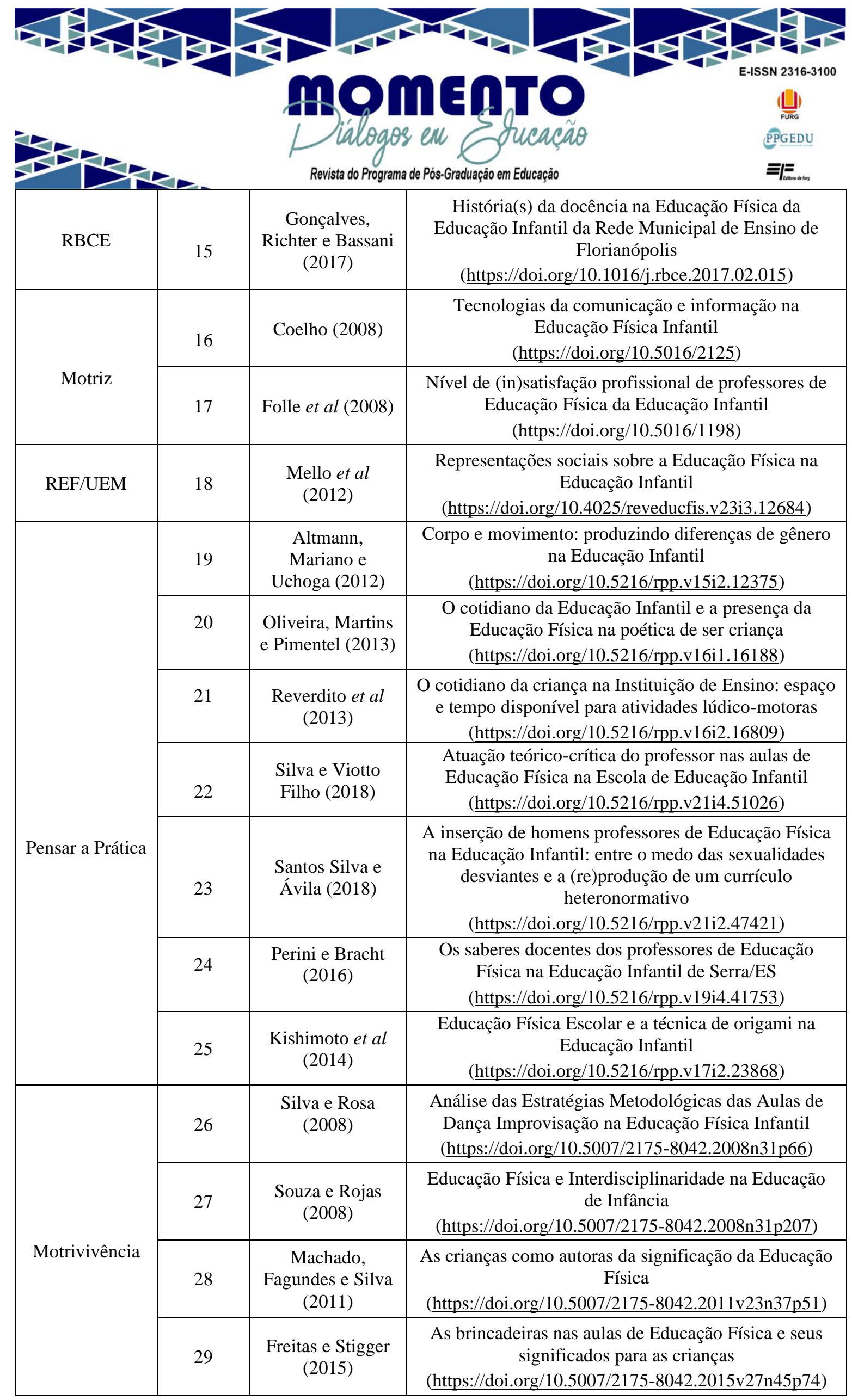




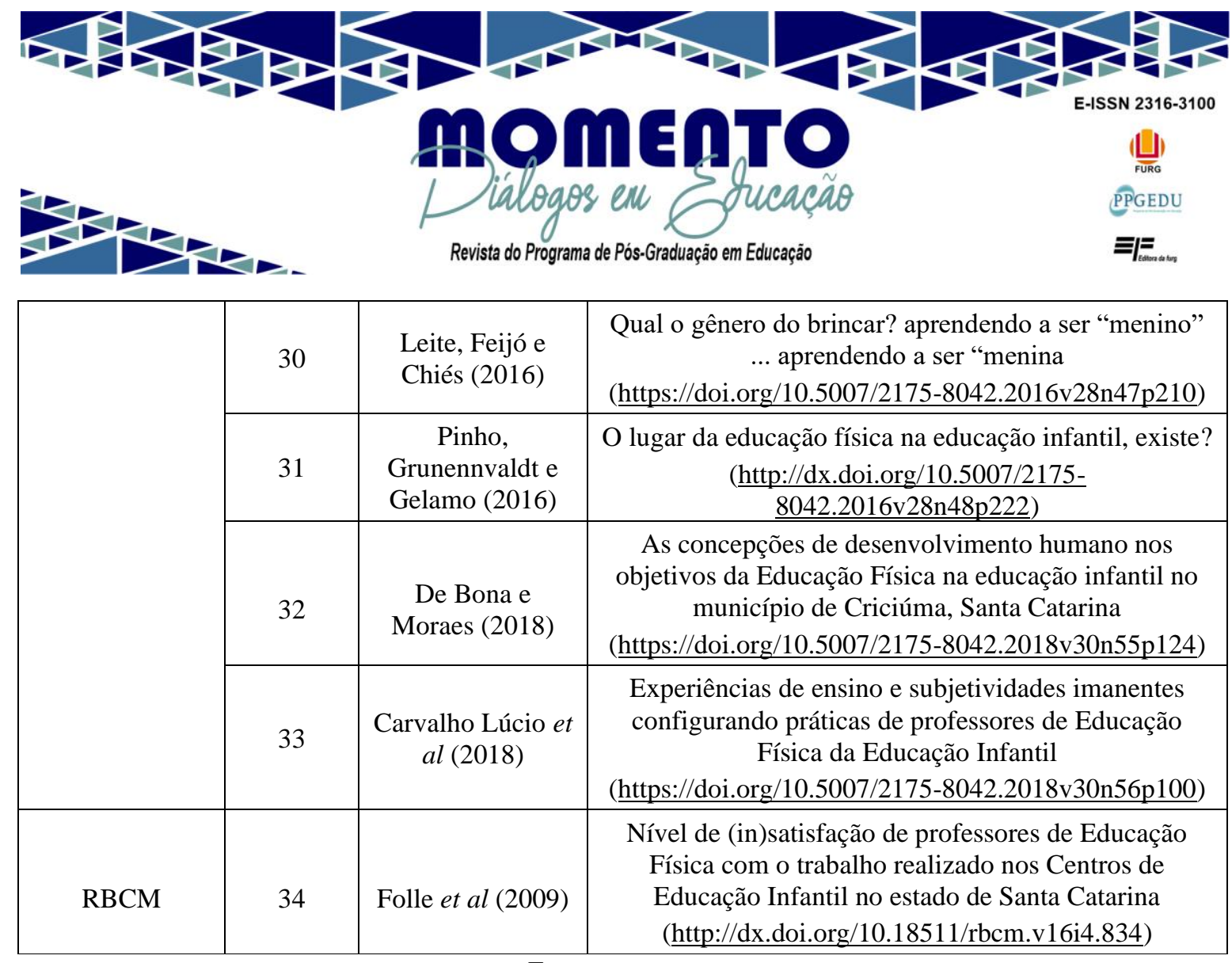

Fonte: os autores

Nesta direção, foram estabelecidas as seguintes sessões de análise: a) Mapeamento dos autores da produção científica sobre a Educação Física na Educação Infantil; b) Procedimentos metodológicos abordados nas produções científicas sobre a Educação Física na Educação Infantil; e c) Principais temáticas das pesquisas selecionadas sobre Educação Física na Educação Infantil. Ressalta-se também que, para melhor organização, adotou-se a frequência (f) e a porcentagem (\%) para elucidar os achados que apresentaram similaridades ou disparidades.

\section{Resultados e Discussão}

\section{Mapeamento dos autores da produção científica sobre a Educação Física na Educação Infantil}

A partir do levantamento dos artigos que tratam da temática da Educação Física na Educação Infantil, nas bases de dados selecionadas, foi possível identificar os autores responsáveis pelas produções, bem como as regiões a que pertencem no cenário brasileiro (Tabela 1), sendo um total de 87 autores nas 34 produções analisadas. 


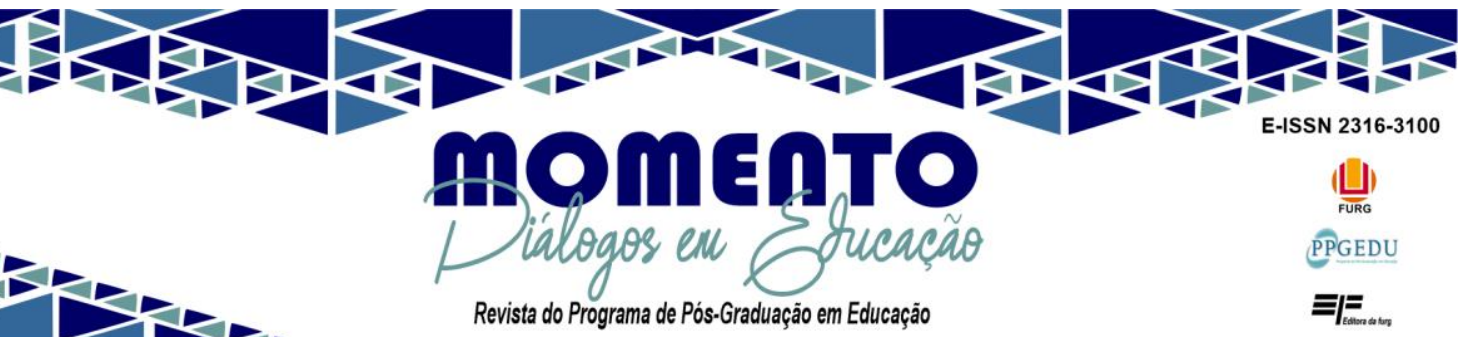

Tabela 1: Quantificação de autores de acordo com a produção científica e a região.

Produções

\section{Regiões}

(34) Sul

Sudeste

Centro Oeste

Nordeste

Norte

\begin{tabular}{cccccc}
$\begin{array}{c}\text { Autores por } \\
\text { região }\end{array}$ & 25 & 39 & 15 & 5 & 3 \\
\hline
\end{tabular}

Fonte: os autores.

De acordo com a Tabela 1, em relação à região geográfica, destaca-se que o Sudeste obteve a maior concentração de pesquisadores, no que tange à temática Educação Física na Educação Infantil ( $f 39)$, seguido da região Sul $(f 25)$, Centro-Oeste $(f 15)$, Nordeste $(f 5)$ e Norte $(f 3)$. Outro ponto que também foi levantado está ligado às instituições as quais pertencem esses sujeitos pesquisadores (Quadro 2), de forma que a Universidade Federal do Espírito Santo (UFES) se destaca como a instituição que tem o maior número de pesquisadores que abordam o assunto.

Quadro 2: Instituições que possuem dois ou mais pesquisadores.

\begin{tabular}{|c|c|}
\hline Instituição & N $^{\circ}$ de Autores \\
\hline Universidade Federal do Espírito Santo (UFES) & 72 \\
\hline Universidade Federal de Santa Catarina (UFSC) & 6 \\
\hline Faculdade Adventista de Hortolândia (FAH) & 5 \\
\hline Universidade Estadual de Campinas (UNICAMP) & 4 \\
\hline Universidade Federal do Rio Grande do Sul (UFRGS) & 3 \\
\hline Universidade do Estado de Santa Catarina (UDESC) & 3 \\
\hline Universidade Federal da Paraíba (UFPB) & 3 \\
\hline Universidade Federal do Mato Grosso (UFMT) & 3 \\
\hline Universidade Federal do Paraná (UFPR) & 2 \\
\hline Universidade Federal do Rio Grande do Norte (UFRN) & 2 \\
\hline Universidade de Brasília (UNB) & 2 \\
\hline Universidade Feevale - Campus II (FEEVALE) & 2 \\
\hline Universidade do Vale do Itajaí (UNIVALI) & 2 \\
\hline Universidade Federal de Mato Grosso do Sul (UFMS) & 2 \\
\hline Centro Universitário Euro Americano (UNIEURO) & 2 \\
\hline Centro Universitário de Jaguariúna (UNIFAJ) & \\
\hline
\end{tabular}

Fonte: os autores 


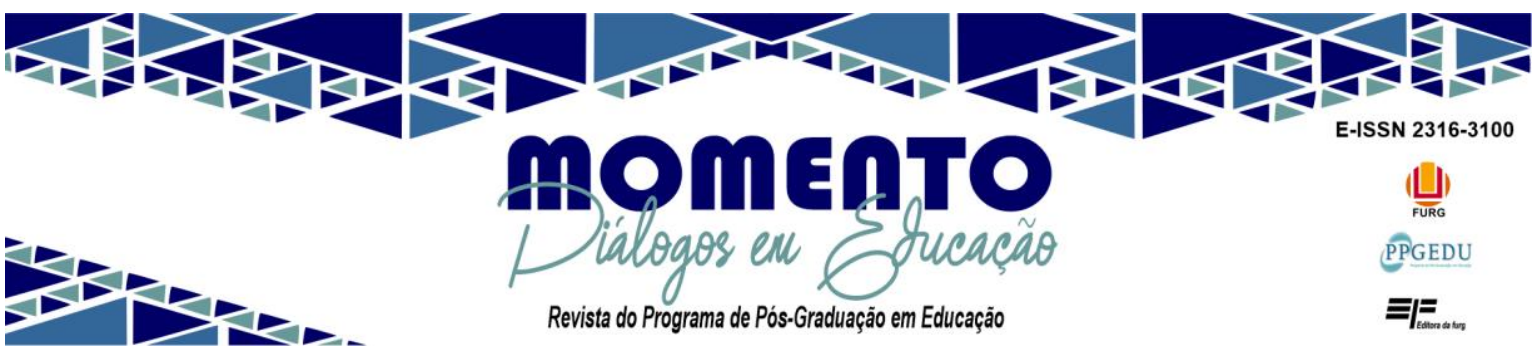

Com base nos dados apresentados acima, nota-se que a Educação Física na Educação Infantil é tema que se constitui como fenômeno de pesquisa em muitas instituições públicas e privadas do Brasil. O destaque do número de pesquisadores da área ligados às regiões Sudeste e Sul do país pode ser inferido, uma vez que são as regiões que apresentam o maior número de Grupos de Pesquisa ligados à Educação Física Escolar (ANVERSA et al, 2017). Ao analisarem o Diretório de Grupos de Pesquisas do Conselho Nacional de Desenvolvimento Científico e Tecnológico, Anversa et al (2017) destacam a prevalência de grupos de pesquisa na região Sudeste com 48,5\% (16 grupos) e na região Sul com 24,2\% (8 grupos), todos voltados para a área da Educação Física Escolar. Os autores destacam que nos últimos anos a busca por grupos de pesquisas voltados para a temática escolar tem aumentado, de maneira que os pesquisadores interessados nessa linha de pesquisa são provenientes de diferentes áreas de formação (graduação, especialização, mestrado profissional, mestrado acadêmico, doutorado), o que abre portas para a produção acadêmica.

Em relação à formação dos pesquisadores encontrados neste estudo, de acordo com a análise do Currículo Lattes de cada um deles, nota-se que a grande maioria é formada somente em Educação Física ( $f 72$ ), embora alguns pesquisadores tenham outras formações como: Educação Física e Administração $(f 1)$, Educação Física e Biomedicina $(f 1)$, Educação Física e Filosofia ( $f$ 2), Educação Física e Fisioterapia $(f 1)$, Educação Física/Teologias e Letras $(f 1)$, Educação Física e Pedagogia $(f 2)$, Educação Física e Psicologia $(f 1)$, Educação Física e Sociologia $(f 1)$, Letras $(f 1)$, Letras e Pedagogia $(f 1)$, Pedagogia $(f 1)$, Psicologia $(f 2)$, Psicologia/Filosofia e Letras $(f 1)$.

Ademais, é evidente nas pesquisas selecionadas a ligação que alguns autores ainda têm com a Educação Física na Educação Infantil, seja como Professores do Ensino Superior que trabalham com disciplinas ligadas à Educação Infantil, Professores da Rede de Ensino, Professores que atuam em cursos de Formação de Professores, ou coordenadores de projetos de extensão e pesquisa voltados para a área da Educação Física Escolar. Portanto, os pesquisadores apresentam interesses diretos e/ou indiretos pela Educação Física inserida na Educação Infantil. Tais interesses possibilitam novos olhares de conhecimento sobre a temática, ainda pouco explorada, uma vez que é uma temática que vem ganhando espaço no cenário brasileiro, ligando novos saberes e ideias para produção de pesquisas voltadas para 


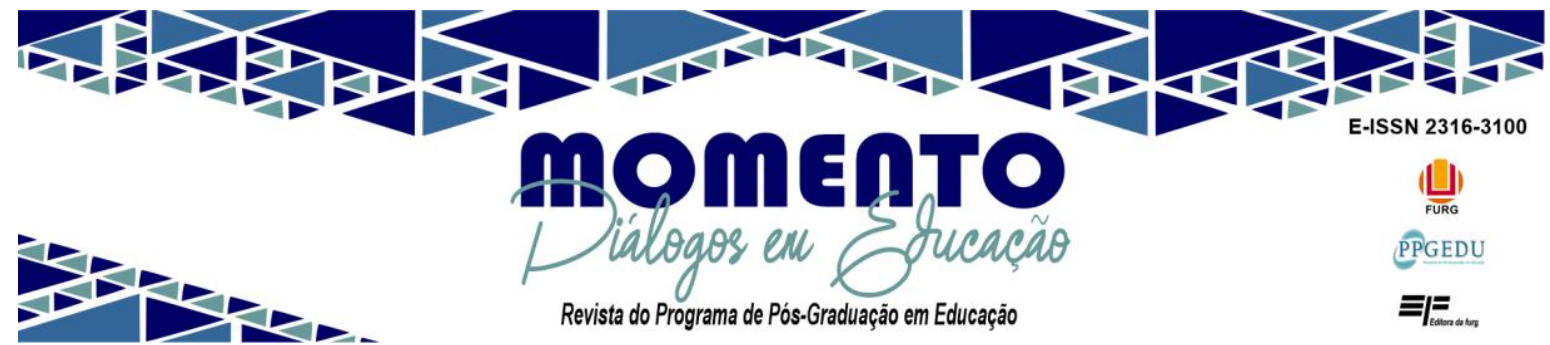

a área entre pesquisadores de distintas instituições.

Dentre os autores dos artigos analisados, estão presentes em duas ou mais publicações os seguintes: José Francisco Chicon, Maria das Graças Carvalho Silva Sá, Ademir de Marco, José Tarcísio Grunennvaldt, André da Silva Mello, Ana Cristina Richter, Alexandra Folle, Lucélia Justino Borges, Raildo da Silva Coqueiro, Juarez Vieira do Nascimento e Daniela Bento Soares. Destacam-se como pesquisadores com maior número de produções os professores José Francisco Chicon e Maria das Graças Carvalho Silva Sá, ambos presentes em três dos 34 artigos selecionados. Eles realizam, em parceria, estudos voltados para a Formação de Professores e Práticas Educacionais Inclusivas, bem como atuam como docentes do curso de Educação Física na UFES.

Os demais autores apresentam linhas de pesquisas relacionadas com a Educação Física, a Educação Infantil, a Prática Pedagógica e o Esporte. Em grande parte, os autores estão ligados aos mesmos projetos de extensão, de acordo com sua região de atuação profissional, e possuem pesquisas que fomentam a importância da Educação Física em diferentes áreas do desenvolvimento humano e das relações humanas, principalmente, no que concerne à criança.

\section{Procedimentos metodológicos adotados nas pesquisas sobre Educação Física na}

\section{Educação Infantil}

A partir do fichamento dos 34 artigos, observa-se a predominância de um método de pesquisa específico, bem como a presença de diferentes tipos e técnicas de coleta e análise dos dados. Porém, alguns dos artigos se assemelham em relação aos instrumentos de coleta de dados e/ou análise das informações (Tabela 2). 


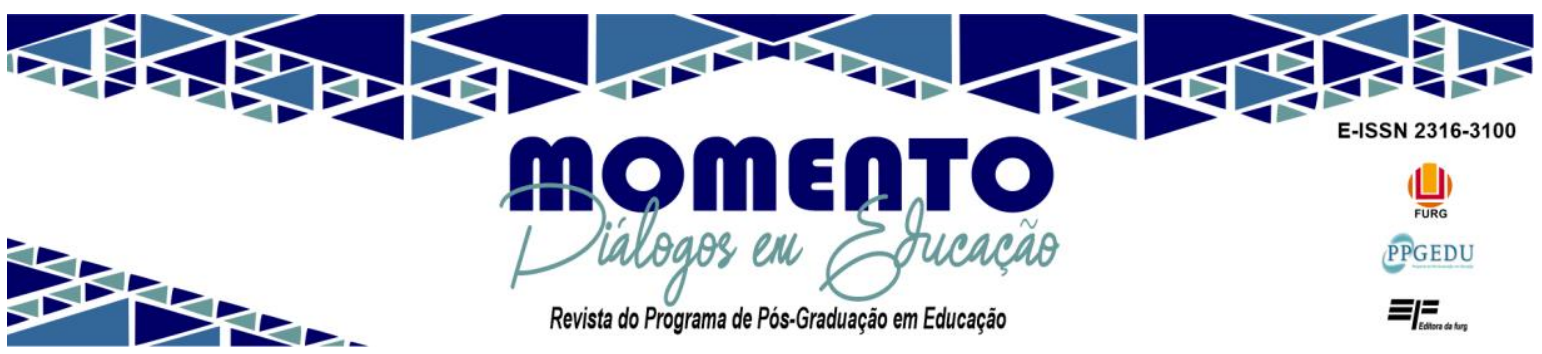

Tabela 2: Procedimentos metodológicos adotados nas pesquisas selecionadas.

\begin{tabular}{cccc}
\hline Tipo de Pesquisa & $\mathbf{f}(\boldsymbol{\%})$ & Instrumento de Coleta & $\mathbf{f}(\boldsymbol{\%})$ \\
\hline & & Observação & $10(37,1 \%)$ \\
& & Entrevista & $(25,9 \%)$ \\
Qualitativa & $27(79,5 \%)$ & Diário de Campo & $5(18,5 \%)$ \\
& & $2(7,4 \%)$ \\
& & Observação + Programa de Intervenção & $1(7,4 \%)$ \\
& Programa de Intervenção & $4(6,7 \%)$ \\
\hline Quantitativa & $6(17,6 \%)$ & Questionário + Entrevista & $1(16,7 \%)$ \\
& & Questionário & $1(16,7 \%)$ \\
\hline \multirow{2}{*}{ Quali-Quantitativa } & $1(2,9 \%)$ & Testes (Manual de Desenvolvimento Motor) & $1(100 \%)$ \\
\hline
\end{tabular}

Fonte: os autores.

Conforme os dados apresentados na Tabela 2, observa-se que as pesquisas qualitativas se destacam na produção do conhecimento sobre a Educação Física na Educação Infantil, totalizando 27 pesquisas com percentual de $79,5 \%$, seguidas de $17,6 \%$ de pesquisas quantitativas e 2,9\% quali-quantitativas. A pesquisa qualitativa apresenta propostas diferenciadas na sua estruturação, levando em consideração a imaginação e a criatividade do pesquisador na elaboração dos trabalhos (SILVA, PILLON, 2019).

Ao analisar os estudos qualitativos, verificou-se que os instrumentos para coleta de dados em sua maioria incluíam a técnica da observação nas aulas de Educação Física, ou seja, a observação das estratégias utilizadas pelos professores ou do espaço concedido a eles no processo de desenvolvimento da criança. Essa técnica está presente nos artigos 1, 3, 6, 7 , 12, 18, 19, 22, 23, 27 (SILVA, ROSA, 2008; HIRAI, CARDOSO, 2009; RICHTER, VAZ, 2010; ALTMANN, MARIANO, UCHOGA, 2012; MELLO et al, 2012; CHICON, SÁ, FORTES, 2013; ANDRADE FILHO, 2013; FREITAS, STIGGER, 2015; LEITE, FEIJÓ, CHIÉS, 2016; BARBOSA, MARTINS, MELLO, 2017), os quais abordavam em sua metodologia possibilidades para um crescimento tanto do aluno quanto do professor diante de suas práticas e propostas pedagógicas.

Destaca-se o artigo 3 (ANDRADE FILHO, 2013) que enfatiza o espaço da Educação Física na Educação Infantil em uma creche de Florianópolis; o artigo busca enfatizar que as práticas corporais das crianças precisam ser desenvolvidas e trabalhadas de maneira segura, visto que, segundo a pesquisa, a realidade observada evidenciou situações marcadas por 


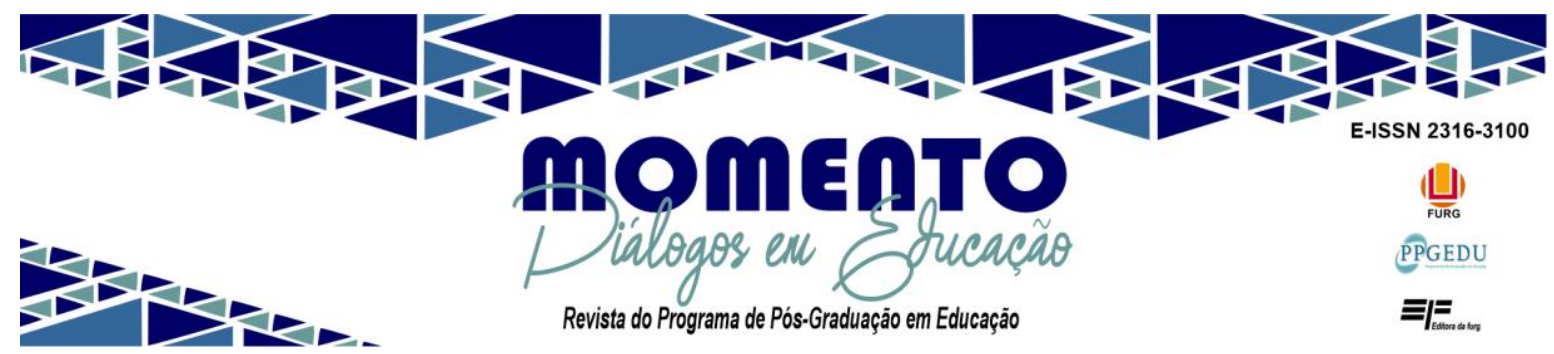

momentos como: castigo e ameaças, práticas de exclusão e preconceito. Assim, o autor reforça a importância de que, no mundo contemporâneo, os espaços, a percepção sobre como e quando se movimentar possam fixar o lugar da Educação Física e legitimar sua presença na Educação Infantil.

As entrevistas também foram utilizadas como recurso metodológico. Elas buscaram compreender os saberes dos professores de Educação Física em relação à Educação infantil, desde seus processos de formação docente até a atuação escolar. Essa técnica foi adotada nos artigos 5, 13, 15, 24, 25, 31, 32 (RODRIGUES, FIGUEIREDO, 2011; PINHO, GRUNENNVALDT, GELAMO, 2016; PERINI, BRACHT, 2016; GONÇALVES, RICHTER, BASSANI, 2017; TONIETTO, GARANHANI, 2017; BONA, MORAES, 2018; SILVA, ÁVILA, 2018;).

O diário de campo foi o instrumento utilizado nos artigos 4, 8, 10, 14, 29 (REVERDITO et al, 2013; CHICON, SÁ, 2011; CHICON et al, 2016; SURDI, MELO, KUNZ, 2016; MACEDO, NEIRA, 2017), nos quais são identificados resultados sobre a inclusão e os processos de desenvolvimento da criança no seu brincar. A maioria das pesquisas supracitadas objetivaram tanto a mediação do professor e suas respectivas ações quanto a participação da própria criança no cotidiano da sala de aula, com vistas a potencializar o seu desenvolvimento por meio de práticas corporais.

Com relação aos estudos de cunho quantitativo, ou seja, os artigos 16, 17, 20, 34 (COELHO, 2008; FOLLE et al, 2008; SOUZA, ROJAS, 2008; FOLLE et al, 2009), todos os autores utilizaram o questionário como instrumento de coleta de dados. No entanto, eles se diferenciam enquanto organização, protocolo e forma de coleta utilizada. Os artigos 17 e 20 utilizaram questionários informais para obtenção de respostas que diziam respeito à qualidade do ensino de Educação Física na Educação Infantil e à interdisciplinaridade na Educação de infância. Os artigos 17 e 34 foram elaborados pelos mesmos autores, abordando o nível de (in)satisfação profissional de professores de Educação Física inseridos na Educação Infantil do Estado de Santa Catarina, os mesmos obtiveram as informações por meios dos questionários validados para o contexto brasileiro. Ressalta-se que a maioria dos professores apresentaram em ambas as pesquisas satisfação com sua profissão e com o trabalho nos Centros de Educação Infantil, observando-se apenas os motivos intrínsecos da profissão.

Por fim, o Artigo 2 (SPESSATO et al, 2009), que possui cunho quali-quantitativo, 


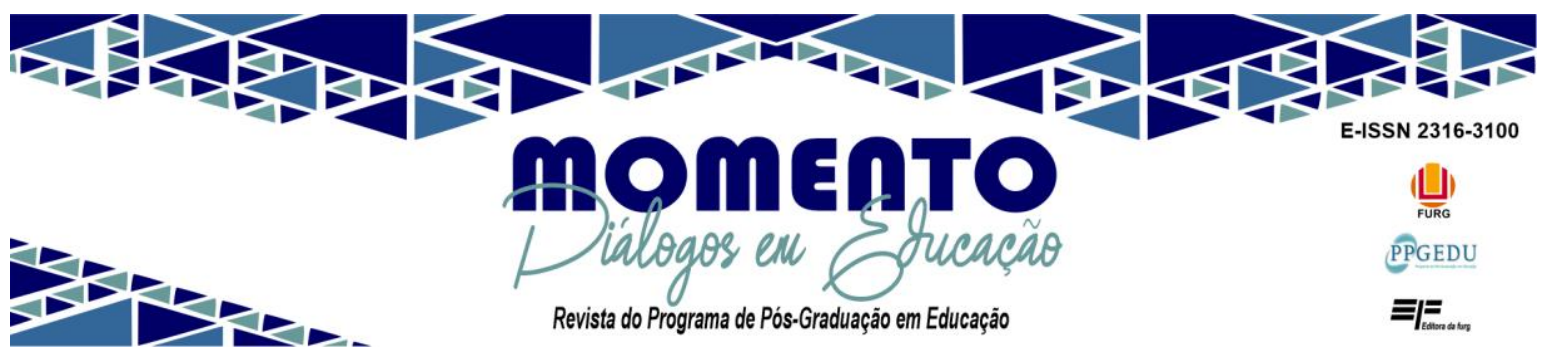

investigou o processo de desenvolvimento do comportamento dos bebês e descreveu o contexto das creches por meio da descoberta de delineamentos bioecológicos. A pesquisa apoiou-se em três estudos de caso realizados com bebês em uma intervenção motora dentro das creches no primeiro ano de vida. O estudo foi realizado em duas creches de Porto Alegre, as quais recebem crianças vindas de famílias de baixa renda. A primeira com 11 bebês por atendente e a outra com oito bebês por atendente, ainda que, em nenhuma das creches, as educadoras possuíssem formação de nível superior, somente fundamental e médio. As intervenções foram realizadas três vezes por semana, durante o período de dois meses, somando o total 18 intervenções. Cada sessão era dividida em três partes (perseguição visual, exploração sensório-motora e deslocamento) que eram registradas por meio de filmagens e um diário de campo. Em uma das creches, havia escassez de estruturas diferentes, ambientes e materiais para atender as crianças, ao passo que na outra creche, havia mais recursos em questão de brinquedos para o desenvolvimento dos bebês, mas, ainda assim, eles tinham suas possibilidades de descobertas limitadas, devido à carência de recursos oferecidos pelo local de ensino.

Enfoque temático abordado na produção científica sobre a Educação Física na Educação Infantil

Por meio da análise dos artigos selecionados acerca da Educação Física na Educação Infantil, foram evidenciadas temáticas principais e secundárias que configuram o enfoque dado às produções científicas apresentadas no cenário brasileiro (Figura 2).

Figura 2: Enfoque temático da produção sobre a Educação Física na Educação Infantil. 

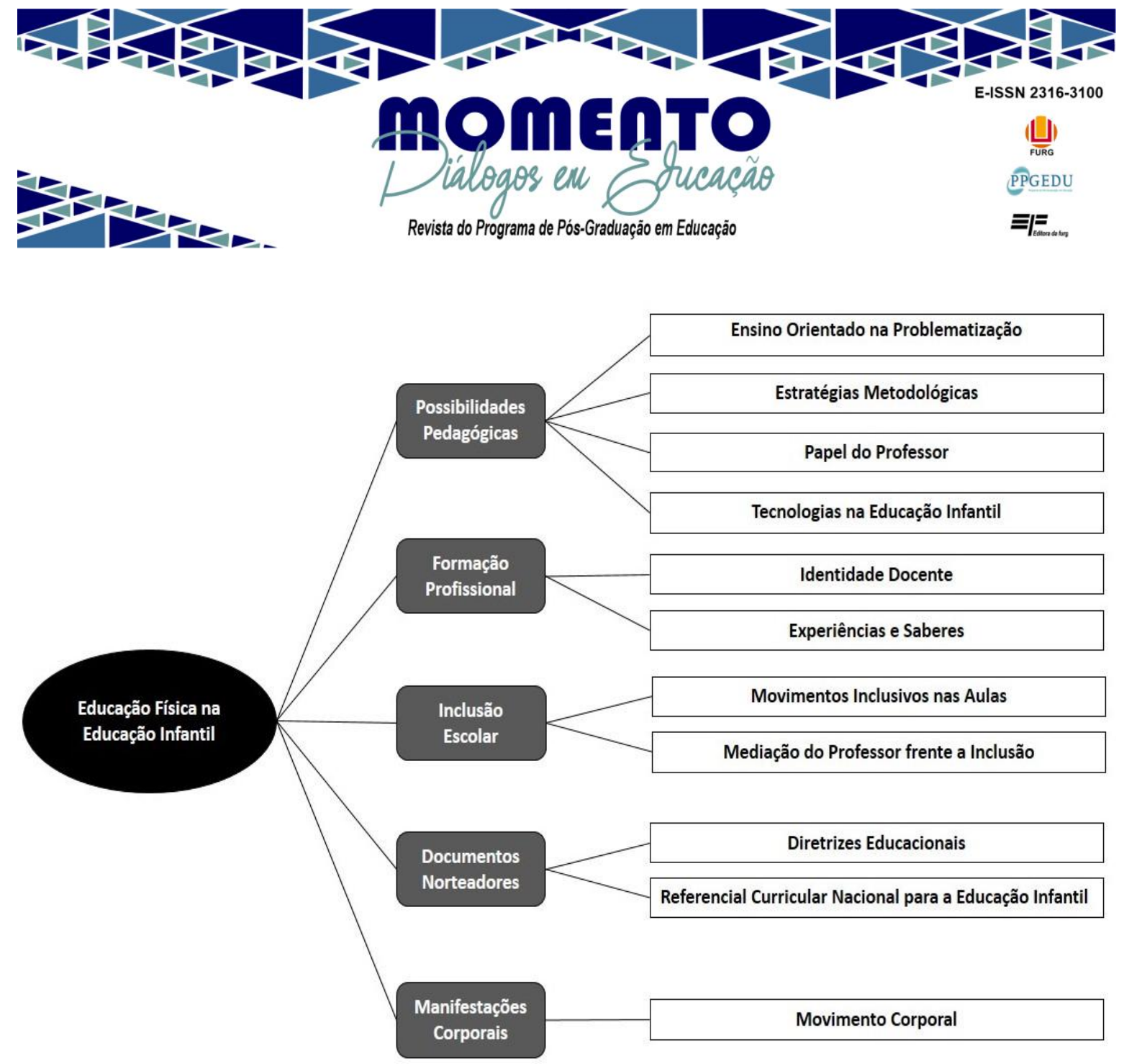

Fonte: os autores

Os artigos com enfoque temático sobre a Educação Física na Educação Infantil são apresentados por meio de cinco temáticas principais (primárias), elencadas a seguir com seus respectivos artigos: Possibilidades Pedagógicas (COELHO, 2008; FOLLE et al, 2008; SILVA, ROSA, 2008; SOUZA, ROJAS, 2008; HIRAI, CARDOSO, 2009; FOLLE et al, 2009; SPESSATO et al, 2009; MACHADO, FAGUNDES, SILVA, 2011; REVERDITO et al, 2013; KISHIMOTO et al, 2014; FREITAS, STIGGER, 2015; LEITE, FEIJÓ, CHIÉS, 2016; PERINI, BRACHT, 2016; PINHO, GRUNENNVALDT, GELAMO, 2016; GONÇALVES, GOMES-DA-SILVA, ANDRADE, 2017; MACEDO, NEIRA, 2017; BONA, MORAES, 2018; LÚCIO et al, 2018; SILVA, VIOTTO FILHO, 2018); Formação Profissional (RODRIGUES, FIGUEIREDO, 2011; OLIVEIRA, MARTINS, PIMENTEL, 2013; GONÇALVES, RICHTER, BASSANI, 2017; TONIETTO, GARANHANI, 2017; SILVA, ÁVILA, 2018; ); Inclusão Escolar (CHICON, SÁ, 2011; CHICON, SÁ, FORTES, 2013; CHICON et al, 2016)) Documentos Norteadores (MELLO et al, 2012; SOARES, PRODÓCIMO, DE MARCO, 2016) Manifestações Corporais (RICHTER, VAZ, 2010; 


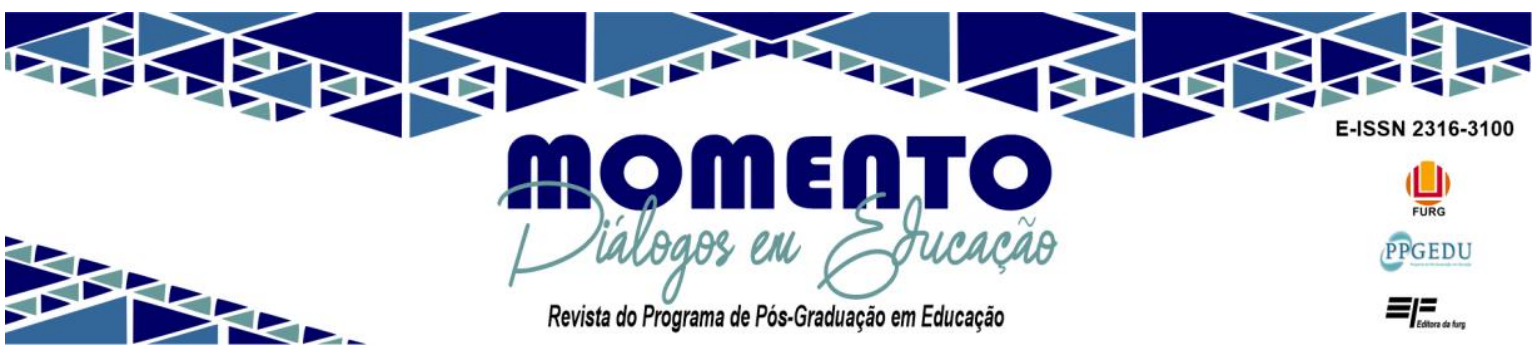

MARIANO, UCHOGA, 2012; ANDRADE FILHO, 2013; SURDI, MELO, KUNZ, 2016; BARBOSA, MARTINS, MELLO, 2017).

Sobre a temática primária Possibilidades Pedagógicas, Lacerda e Silva (2015) destacam que elas podem ser conceituadas como recursos disponíveis na educação, que ampliam as possibilidades pedagógicas da prática docente, traçando caminhos para melhorias na aprendizagem. As pesquisas que se enquadram nessa temática são as seguintes: 1, 2, 11, 14, 19, 20, 21, 22, 23, 24, 25, 30, 32 e 33 (SILVA, ROSA, 2008; SOUZA, ROJAS, 2008; MACHADO, HIRAI, CARDOSO, 2009; SPESSATO et al, 2009; MACHADO, FAGUNDES, SILVA, 2011; KISHIMOTO et al, 2014; FREITAS, STIGGER, 2015; LEITE, FEIJÓ, CHIÉS, 2016; PERINI, BRACHT, 2016; PINHO, GRUNENNVALDT, GELAMO, 2016; GONÇALVES, GOMESDA-SILVA, ANDRADE, 2017; MACEDO, NEIRA, 2017; BONA, MORAES, 2018; SILVA, VIOTTO FILHO, 2018); essas pesquisas focalizam as possiblidades pedagógicas em diferentes situações e estratégias de ensino na Educação Física Infantil.

No artigo 1, Hirai e Cardoso (2009) buscam compreender possibilidades pedagógicas para a realização do ensino orientado na Educação Física Infantil, em um Núcleo de Educação Infantil no município de Florianópolis. Diante da necessidade de pesquisas da área com a realidade escolar, os autores analisaram a possibilidade de concepção de "aula aberta", como um dos referenciais teóricos que afirmam sua prática pedagógica. Por isso, a mudança deve vir do próprio educador mediante sua predisposição para transformar o cotidiano escolar.

Possibilidades Pedagógicas subdivide-se em outras quatro temática secundárias, a saber: Ensino Orientado na Problematização, Estratégias Metodológicas, Papel do professor e Tecnologias na Educação Infantil. Considerando a temática secundária Estratégias Metodológicas (Figura 2), tem-se o artigo 19, desenvolvido por Silva e Rosa (2008). Para tratar desse tema, os autores, apresentam diferentes estratégias para o ensino na Educação Física Infantil, sendo eles: o diálogo (comunicação), a motivação, o despertar da curiosidade (com materiais de apoio) e a demonstração. Ainda no que concerne à subtemática Estratégias Metodológicas, nota-se que o artigo 21, escrito por Machado, Fagundes e Silva (2011), utiliza-se de uma metodologia na qual os planejamentos e a elaboração dos planos se configuraram com base nas vivências, experiências e reflexões.

A temática secundária Papel do Professor mostra-se ainda mais importante na 


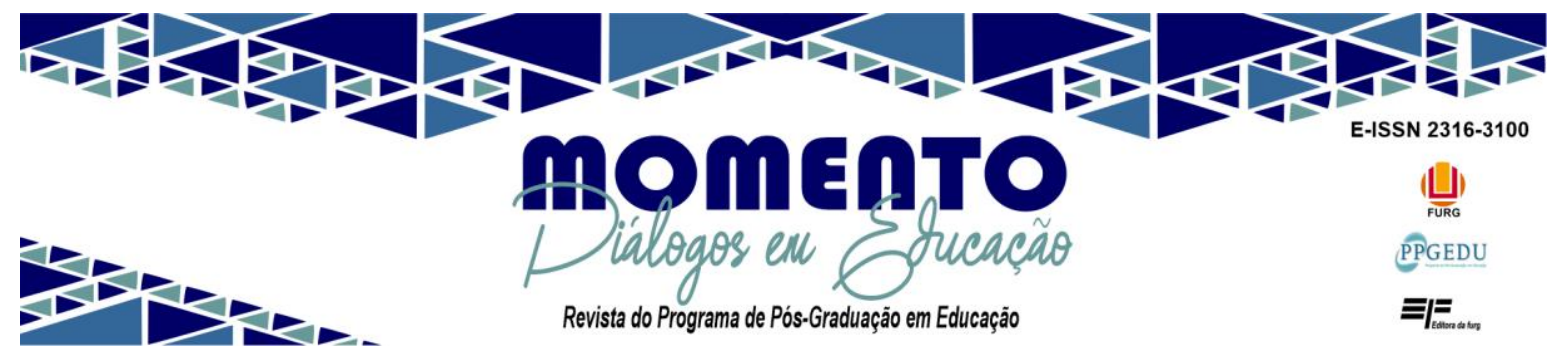

Educação Física Infantil, pois, nessa idade, a criança tem concepções egocêntricas de como resolver situações problemas. Diante disso, o professor deve colocar-se como mediador da situação, permitindo que a criança se expresse e entenda o significado de suas próprias ações (QUINQUIOLO, 2017). A proposta de pesquisa que o artigo 20 (SOUZA, ROJAS, 2008) coloca em pauta é a interdisciplinaridade do Professor de Educação Física nas aulas. Para os autores, o professor deve apoiar-se na especificidade pedagógica da Educação Física, como área de conhecimento que trata das práticas corporais de movimento e vincular seus conteúdos com as demais áreas do saber.

Por fim, no grupo das Possibilidades Pedagógicas, também se encontra como temática secundária o uso das Tecnologias na Educação Infantil, uma questão que é abordada pelo artigo 17 (COELHO, 2008). Esse artigo se caracteriza pelo destaque dos benefícios do uso da tecnologia para o registro do processo individual dos alunos. Segundo o autor, o uso da tecnologia aumenta de forma significativa a eficiência do trabalho docente na Educação Física infantil.

A temática principal Formação Profissional está subdividida em duas temáticas secundárias. Os artigos que abrangem essa temática principal são: 5, 13, 15, 16, 26, 28, 31 e 34 (FOLLE et al, 2008; FOLLE et al, 2009; RODRIGUES, FIGUEIREDO, 2011; OLIVEIRA, MARTINS, PIMENTEL, 2013; GONÇALVES, RICHTER, BASSANI, 2017; TONIETTO, GARANHANI, 2017; LÚCIO et al, 2018; SILVA, ÁVILA, 2018). São apresentadas duas temáticas secundárias que caracterizam todos esses estudos, sendo elas: Identidade Docente do professor de Educação Física na Educação Infantil e Experiências e Saberes na Educação Física integrada à cultura infantil (Figura 2). Quanto à temática secundária Identidade Docente, cita-se o artigo 5, de autoria de Rodrigues e Figueiredo (2011), que busca compreender a construção da identidade docente de professoras ligadas à área da Educação Física e que atuam na Educação Infantil. As autoras destacam que estudar as possibilidades de desenvolvimento pessoal e profissional durante o trabalho no âmbito educacional, a partir dos conhecimentos incluídos na formação, traz novos saberes para enriquecer a formação profissional em todas as etapas do ensino.

Paralelamente ao artigo 5, o artigo 13, proposto por Tonietto e Garanhani (2017), buscou compreender os saberes dos professores de Educação Física escolar a partir da cultura infantil. Observou-se que quando os professores buscam formas de ampliar seus 


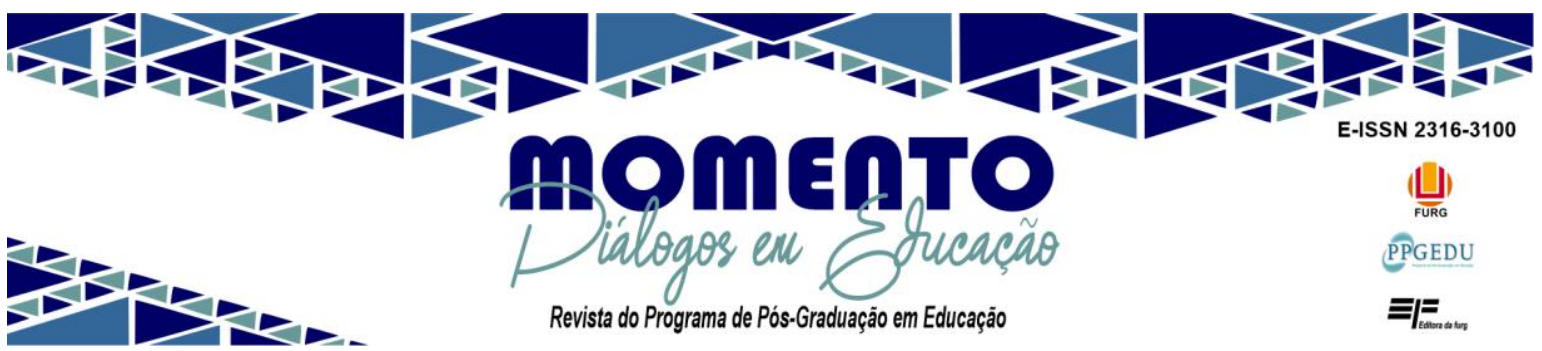

conhecimentos sobre as crianças, passam a dar abertura as suas formas de expressão.

A terceira temática principal (Figura 2) estabelecida por este artigo denomina-se Inclusão Escolar (CHICON, SÁ, 2011; CHICON, SÁ, FORTES, 2013; CHICON et al, 2016), a qual também se subdivide em outras duas temáticas secundárias: Movimentos Inclusivos na Aulas e Mediação do Professor Perante a Inclusão. Os artigos 7 e 8 abordam as condições para construção e mediação dos professores por meio de projetos inclusivos que possam desenvolver a interação entre as crianças com deficiência (Autismo e Paralisia cerebral) e as crianças sem deficiências, a fim de consolidar as ações promovidas pelos professores nos locais de ensino. Em contrapartida, no artigo 4 (CHICON, SÁ, 2011), os autores enfatizam conhecer os processos educacionais que se desdobram nas aulas de Educação Física. Entretanto, diante desse contexto inclusivo, requer-se do profissional muito mais que ações pedagógicas, e sim habilidades que lhe tragam autonomia para novos olhares que assegurem e potencializem o desenvolvimento das crianças em diferentes contextos educacionais.

Outra temática principal encontrada nesta pesquisa diz respeito aos Documentos Norteadores que embasam a Educação Física na Educação Infantil. Nos artigos 9 e 18 (SOARES, PRODÓCIMO, DE MARCO, 2016; MELLO et al, 2012), os pesquisadores enfatizam dois pontos presentes no Referencial Curricular Nacional para a Educação Infantil e nas Diretrizes Curriculares Nacionais para a Educação Infantil, os quais falam sobre a importância do trabalho conjunto na área de conhecimento da Educação Física, de modo que se faça presente na implementação da disciplina. Nos estudos analisados, foi possível identificar que a associação da dimensão "Conhecimento de Mundo" a eixos como o movimento é um possível ponto de discussão sobre o poder da Educação Física no contexto interdisciplinar, bem como as possíveis estratégias pedagógicas que podem ser realizadas na Educação Infantil de forma conjunta diante das linhas de conhecimentos dos professores regentes das instituições.

Finalmente, mas não menos importante, destaca-se a quinta temática principal evidenciada nesta pesquisa, isto é, as Manifestações Corporais dos alunos da Educação Infantil. Tendo em vista que a Educação Física trabalha a partir das manifestações corporais dos alunos, é possível observar situações ricas entre eles, que expressam, de maneira natural, seus gostos, suas atitudes interiorizadas pelo patrimônio herdado (MANZINI, 2017). 


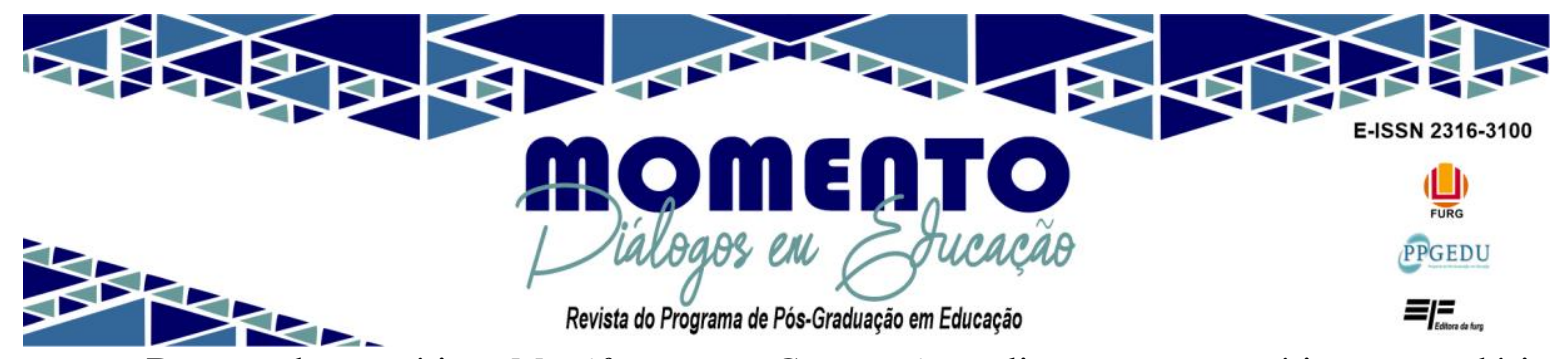

Dentro da temática Manifestações Corporais, salienta-se a temática secundária denominada Movimento Corporal como foco dos estudos 6, 10, 12, 27 e 35 (ALTMANN, MARIANO, UCHOGA, 2012; ANDRADE FILHO, 2013; SURDI, MELO, KUNZ, 2016; BARBOSA, MARTINS, MELLO, 2017). Todos os artigos expressam a importância de se trabalhar o movimento corporal na educação infantil sob orientação de um profissional de Educação Física, uma vez que ele pode proporcionar atividades que estimulem as crianças a perceberem seus recursos corporais, bem como suas capacidades e limitações.

\section{Considerações Finais}

Nesse sentido, diante dos dados obtidos, percebe-se que a Educação Física está inserida de forma parcial nas instituições de ensino, no Brasil, como área de conhecimento conjunta, visto que ainda existem paradigmas na sua implantação como disciplina. Também se destaca que a maioria das produções analisadas consideram a importância de um professor da área na Educação Infantil, bem como a necessidade do trabalho conjunto dos profissionais de Educação Física e dos demais presentes na Educação Infantil.

Sobre os achados desta revisão, ao fazer o mapeamento dos autores, destacou-se que a região Sudeste possui o maior número de pesquisadores, sendo José Francisco Chicon e Maria das Graças Carvalho Silva Sá os autores que realizaram o maior número de pesquisas no âmbito nacional. Ambos dedicaram seus estudos ao tema da inclusão escolar nas aulas de Educação Física na Educação Infantil. Sobre os procedimentos metodológicos abordados, constatou-se que a maioria dos estudos adotaram o método de pesquisa qualitativa, ao passo que as técnicas de coletas de dados mais utilizadas foram as observações e a aplicação de questionários.

Em relação às temáticas, surgiram cinco categorias principais, sendo elas: Possibilidades Pedagógicas, Formação Profissional, Inclusão Escolar, Documentos Norteadores e Manifestações Corporais. As temáticas abordadas refletiram, de modo geral, acerca da importância de se ter um profissional de Educação Física inserido na Educação Infantil, para potencializar o desenvolvimento das crianças nos anos iniciais, a partir de um contexto teórico e prático da disciplina.

Sabe-se que a Educação Física é um componente curricular obrigatório da Educação Infantil, o qual tem seus indicativos apresentados em muitos documentos legais do país, 


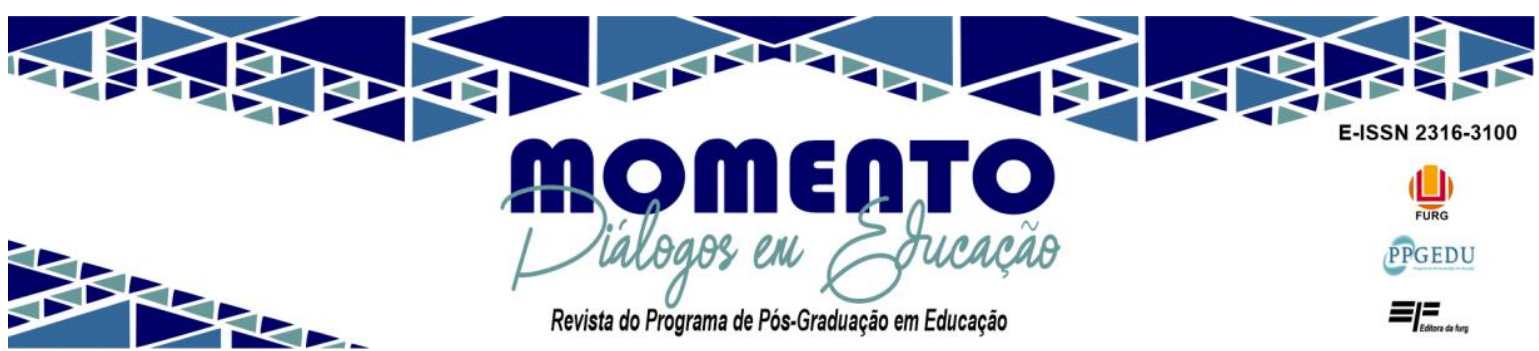

entre eles: RCNEI, DCNEI e BNCC. No entanto, nota-se que a atuação do professor especializado da área não é obrigatória e a intervenção junto aos conhecimentos da área pode ser apresentada de diferentes formas e significados, o que pode gerar potencialidades e/ou barreiras durante o processo de ensino. Assim, ressalta-se a necessidade de conhecer as pesquisas sobre tal temática e seus indicativos e reflexões.

A partir da produção encontrada, surgem algumas inquietações que podem servir de base para estudos futuros, tais como: Em quais dimensões da aprendizagem o professor de Educação Física se torna essencial em sua atuação na Educação Infantil? De que forma o trabalho coletivo entre o professor de Educação Física e o professor Pedagogo pode ser significativo para o processo educacional? Qual a relação estabelecida entre os campos de experiência retratados na BNCC e os conhecimentos da Educação Física? Como os cursos de formação inicial em Educação Física e Pedagogia estão abordando a necessidade de articulação entre as áreas do ensino na Educação Infantil? Com isso, sugerem-se novas pesquisas para ampliar as discussões sobre/com a temática em tela.

\section{Referências}

ALTMANN, H.; MARIANO, M.; UCHOGA, L. A. R. Corpo e movimento: produzindo diferenças de gênero na educação infantil. Pensar a Prática, v. 15, n 2, p. 285-301, 2012.

ANDRADE FILHO, N. F. Observação compreensivo-crítica das experiências de movimento corporal das crianças na educação infantil. Movimento, v. 19, n. 1, p. 55-71, 2013.

AYOUB, E. Reflexões sobre a Educação Física na Educação Infantil. Revista Paulista de Educação Física, São Paulo/SP, p. 01-08, out. 2001.

ANVERSA, A. L. B. et al. Panorama dos grupos de pesquisa em Educação Física Escolar no Brasil. In: Congresso Norte Paranaense de Educação Física Escolar, 8 , 2017. Anais... Londrina, 2017.

BARBOSA, R. F. M.; MARTINS, R. L. D. R.; MELLO, A. S. Brincadeiras lúdicoagressivas: tensões e possibilidades no cotidiano na educação infantil. Movimento, v. 23, n. 1, p. 159-170, 2017.

BONA, B. C.; MORAES, D. L. As concepções de desenvolvimento humano nos objetivos da Educação Física na educação infantil no município de Criciúma, SC. Motrivivência, v. 30, n. 5, p. 124-139, 2018. 


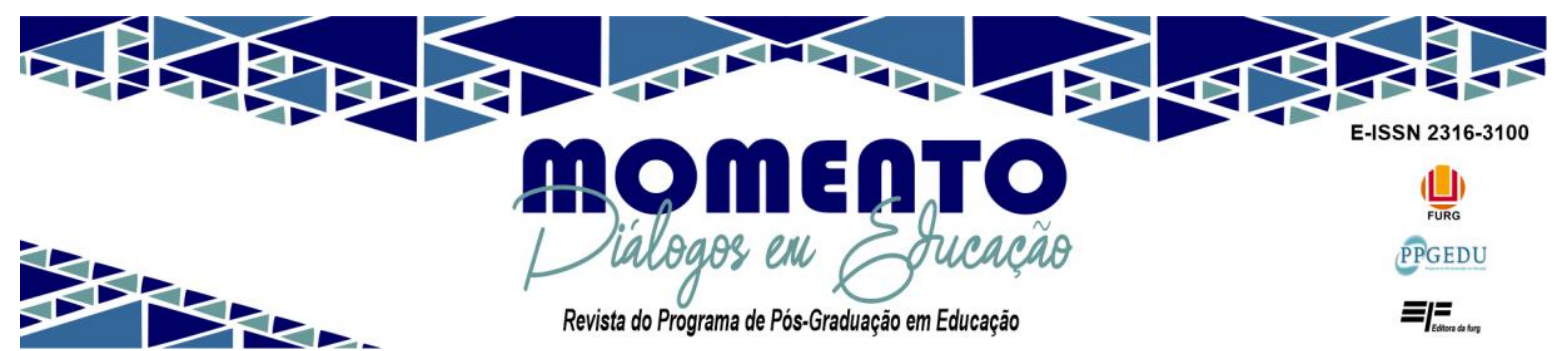

BRASIL. Ministério da Educação. Lei n. 9.394/96, de 20 de dezembro de 1996. Estabelece as diretrizes e bases da educação nacional. Brasília, DF: MEC, 1996.

BRASIL. Ministério da Educação. Base Nacional Comum Curricular. Brasília, DF: MEC, 2017.

BRASIL. Ministério da Educação. Diretrizes Curriculares Nacionais para a Educação Infantil. Brasília, DF: MEC, 2013.

BRASIL. Ministério de Educação. Referencial curricular nacional para Educação Infantil. Brasília, DF: MEC, 1998.

CARVALHO LÚCIO, G. A. et al. Experiências de ensino e subjetividades imanentes configurando práticas de professores de Educação Física da educação infantil. Motrivivência, v. 30, n. 56, p. 100-119, 2018.

CHICON, J. F., et al. Educação física e inclusão: A mediação pedagógica do professor na brinquedoteca. Movimento, v. 22, n. 1, p. 279-292, 2016.

CHICON, J. F.; SÁ, M. C. S. Inclusão na educação física escolar: considerações sobre a constituição da subjetividade humana. Movimento, v. 17, n. 1, p. 41-58, 2011.

CHICON, J. F.; SÁ, M. C. S.; FONTES, A. S. Atividades lúdicas no meio aquático: possibilidades para a inclusão. Movimento, v. 19, n. 2, p. 103-122, 2013.

COELHO, C. R. B. Tecnologias da comunicação e informação na Educação Física Infantil. Revista Motriz, v. 14, n. 3, p. 337-345, 2008.

FARIAS, U. et al. Análise da produção do conhecimento sobre a Educação Física na Educação Infantil. Movimento, v. 25, p. 25058, 2019.

FOLLE, A. et al. Nível de (in) satisfação profissional de professores de Educação Física da Educação Infantil. Revista Motriz, v. 14, n. 2, p. 124-134, 2008.

FOLLE, A. et al. Nível de (in) satisfação profissional de professores de Educação Física nos Centros de Educação Infantil no estado de Santa Catarina. Revista Brasileira de Ciência e Movimento, v. 16, n. 4, p. 1-21, 2009.

FREITAS, M. V.; STIGGER, M. P. As brincadeiras nas aulas de Educação Física e seus significados para as crianças. Motrivivência, Florianópolis, v. 27, n. 45, p. 74-83, 2015.

GAllahue, D.; OZMUN, J.; GOODWAY, J. Compreendendo o Desenvolvimento Motor. 3 ed. São Paulo: Phorte, 2013.

GONÇALVES, D. M. O.; GOMES-DA-SILVA, P. N.; ANDRADE, F. C. B. No princípio é o ludens: integração do self do bebê através do brincar em creche. Movimento, v. 23, n. 2, 


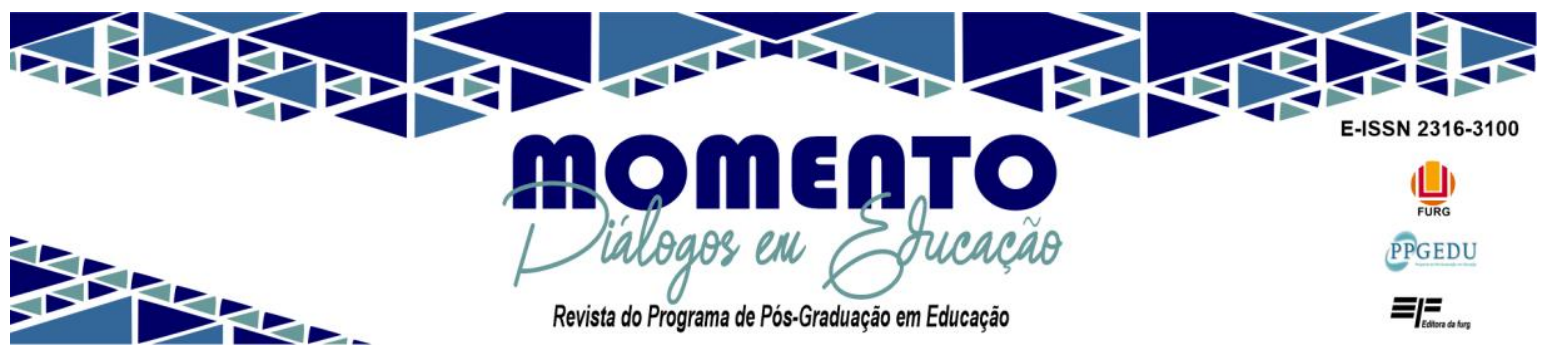

p. 617-362, 2017.

GONÇALVES, D.; RICHTER, A. C.; BASSANI, J. J. História (s) da docência na educação física da Educação Infantil da Rede Municipal de Ensino de Florianópolis. Revista Brasileira de Ciências do Esporte, v. 39, n. 4, p. 362-370, 2017.

HIRAI, R. T.; CARDOSO, C. L. Possibilidades para o ensino orientado na problematização: para a realização da concepção de" aulas abertas às experiências". Movimento, v. 15, n. 1, p. 99-116, 2009.

KISHIMOTO, S. T. et al. Educação física escolar e a técnica de origami na educação infantil. Pensar a Prática, v. 17, n. 2, p. 359-376, 2014.

LACERDA, A. L.; SILVA, T. Possibilidades pedagógicas na perspectiva de uma educação online. Caderno Brasileiro de Ensino de Física, v. 32, n. 1, p. 157-179, 2015.

LEITE, L. G.; FEIJÓ, J. P.; CHIÉS, P. V. Qual o gênero do brincar? Aprendendo a ser "menino". Aprendendo a ser "menina". Motrivivência, v. 28, n. 47, p. 210-225, 2016.

MACEDO, E. E.; NEIRA, M. G. A Educação Física na creche: tematizando as práticas corporais. Revista Brasileira de Educação Física e Esporte, v 1, p. 99-106, 2017.

MACHADO, R.; FAGUNDES, B.; SILVA, F. W. As crianças como autoras da significação da Educação Física. Motrivivência, n. 37, p. 51-68, 2011.

MANZINI, B. R. K. A intervenção do professor de educação física no processo de exteriorização da sexualidade das crianças a partir das manifestações corporais, à luz dos pensamentos de Bourdieu. 2017. Dissertação (Mestrado). Faculdade de Ciências e Letras. Universidade Estadual Paulista "Júlio de Mesquita Filho". Araraquara, 2017.

MARTINS, R. L. R. O lugar da Educação Física na Educação Infantil. 2018. Tese (Doutorado). Centro de Educação Física e Desportos. Universidade Federal do Espírito Santo. Vitória, 2018.

MARTINS, R. L. R.; BARBOSA, R. F. M.; MELLO, A. S. Educação Física e Educação Infantil: o estado do conhecimento sobre a formação docente. Arquivos Brasileiros de Educação Física. v. 1, n. 1, p. 135-155, jan./jul. 2018.

MELLO, A. S. et al. Representações sociais sobre a educação física na educação infantil. Revista da Educação Física/UEM, v. 23, n. 3, p. 443-455, 2012.

MELLO, A. S. et al. Por uma perspectiva pedagógica para a Educação Física com a Educação Infantil. Humanidades \& Inovação, v. 7, n. 10, p. 326-342, 2020.

OLIVEIRA, V. J. M.; MARTINS, D. G.; PIMENTEL, N. P. O cotidiano da educação infantil 


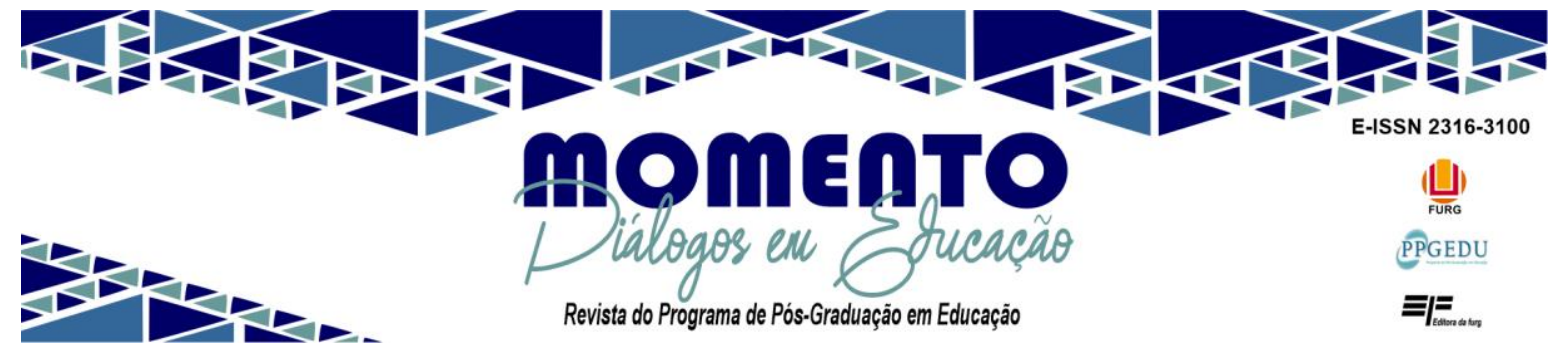

e a presença da educação física na poética de ser criança. Pensar a prática, v. 16, n. 1, p. 118-133, 2013.

PAlMA, Â. P. T. V. OllVeirA, A. A. B. PALMA, J. A. V. Educação Física e a Organização Curricular: Educação Infantil- Ensino Fundamental- Ensino Médio. $2^{\mathrm{a}}$ Ed. Londrina: Eduel, 2010.

PERINI, R.; BRACHT, V. Os saberes docentes dos professores de Educação Física na Educação Infantil de Serra/ES. Pensar a Prática, v. 19, n. 4, p. 953-963, 2016.

PILlON, R.; SILVA, C. L. A Pesquisa qualitativa na Educação Física brasileira: investigando a relação saúde e lazer. Revista Brasileira de Estudos do Lazer, v. 6, n. 1, 2019.

PINHO, V. A.; GRUNENNVALDT, J. T.; GELAMO, K. G. O lugar da educação física na educação infantil, existe? Motrivivência, v. 28, n. 48, p. 222-240, 2016.

QUINQUIOLO, N. O Papel do Professor como Mediador de Conflitos entre Crianças da Educação Infantil. Revista Ciências Humanas - Educação e Desenvolvimento Humano - UNITAU, Taubaté, v. 10, n. 1, p. 116 - 125, 2017.

REVERDITO, R. S. et al. O cotidiano da criança na Instituição de Ensino: Espaço e tempo disponível para atividades lúdico-motoras. Pensar a prática, v. 16, n. 2, p. 355-371, 2013.

RICHARDSON, R. J. Pesquisa social: métodos e técnicas. 4ª ed. São Paulo: Atlas, 2017.

RICHTER, A. C.; VAZ, A. F. Educação Física, educação do corpo e pequena infância: interfaces e contradições na rotina de uma creche. Movimento, v. 16, n. 1, p. 53-70, 2010.

RODRIGUES, R. M.; FIGUEIREDO, Z. C. Construção identitária da professora de Educação Física em uma instituição de educação infantil. Movimento, v. 17, n. 4, p. 65-81, 2011.

SANTOS SILVA, A. L.; ÁVILA, R. S. A inserção de homens professores de Educação Física na Educação Infantil: entre o medo das sexualidades desviantes e a (re) produção de um currículo hétero-normativo. Pensar a Prática, v. 21, n. 2, p. 433-443, 2018.

SILVA, J. R.; VIOTTO FILHO, I. A. T. Atuação teórico-crítica do professor nas aulas de educação física na escola de educação infantil. Pensar a Prática, v. 21, n. 4, p. 786-795, 2018.

SILVA, Q.; ROSA, M. V. Análise de estratégias metodológicas das aulas de dança improvisação na educação física infantil. Motrivivência, v. 20, n. 31, p. 66-78, 2008.

SILVEIRA, V. S.; BOM, F. C. A conceituação sobre a importância da Educação Física e as propostas pedagógicas pelos professores da Educação Infantil. In: Semana de Ciência e 


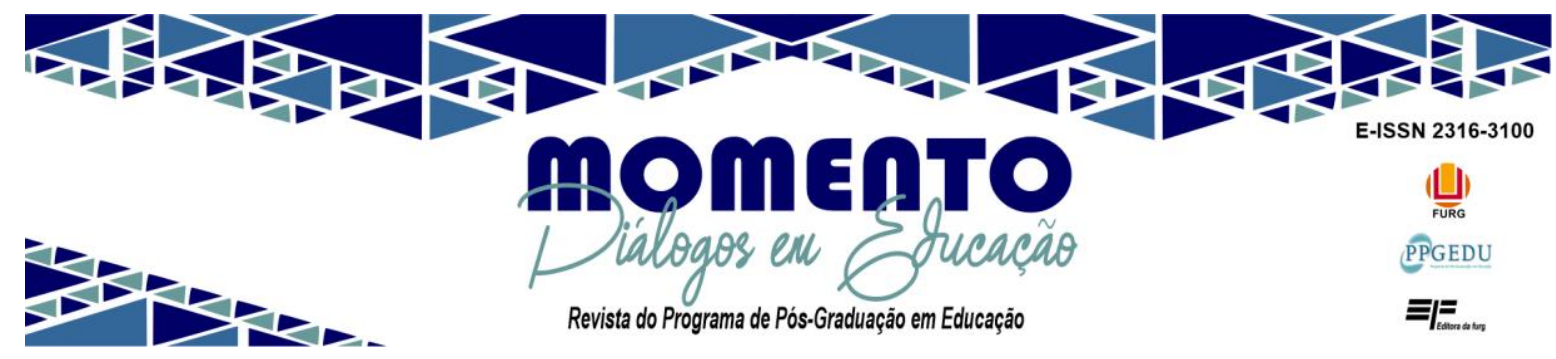

Tecnologia, VIII, 2017. Anais... Criciúma, p. 4, 2017.

SOARES, B. D.; PRODÓCIMO, E; MARCO, A. D. O dialogo na educação infantil: O Movimento, a Interdisciplinaridade e a Educação Física. Movimento, v. 22, n. 4, p. 1195 1208, 2016.

SOUZA, M.; SILVA, M.; CARVALHO, R. Revisão integrativa: o que é e como fazer. Einstein (São Paulo), v. 8, n. 1, p. 102-106, 2010.

SOUZA, R. S. E.; ROJAS, J. Educação Física e Interdisciplinaridade na Educação de Infância. Motrivivência, v. 20, n. 31, p. 207-222, 2008.

SURDI, A. C.; MELO, J. P.; KUNZ, E. O brincar e o se-movimentar nas aulas de Educação Física Infantil: realidades e possibilidades. Movimento, v. 22, n. 2, p. 459-470, 2016.

SPESSATO, B. C. et al. Educação infantil e intervenção motora: um olhar a partir da teoria bioecológica de Bronfenbrenner. Movimento, v. 15, n. 4, p. 147-173, 2009.

TONIETTO, M. R.; GARANHANI, M. C. A cultura infantil e a relação com os saberes da Educação Física na escola. Movimento, v. 23, n. 2, p. 517-528, 2017.

Submissão em: 04-05-2021

Aceito em: 02-09-2021 